\title{
MODIFICATIONS TO THE GLOBAL AND INTERACTIVE SHEAR BUCKLING ANALYSIS METHODS OF TRAPEZOIDAL CORRUGATED STEEL WEBS FOR BRIDGES
}

\author{
Su-mei Liu ${ }^{1,2}$, Han-shan Ding ${ }^{1, *}$, Luc Taerwe ${ }^{2,3}$ and Wouter De Corte ${ }^{2}$ \\ ${ }^{1}$ School of Civil Engineering, Southeast University, Nanjing, 211189, China \\ ${ }^{2}$ Department of Structural Engineering, Faculty of Engineering and Architecture, Ghent University, Ghent, 9000, Belgium \\ ${ }^{3}$ College of Civil Engineering, Tongji University, Shanghai, 200092, China \\ * (Corresponding author: E-mail: hsding@seu.edu.cn)
}

\section{A B S T R A C T}

The value of the global shear buckling coefficient $k_{g}$ and the formula for the interactive shear buckling stress of corrugated steel webs (CSWs) are still the subject of debate. In this study, firstly, the analytical formulas for the global and interactive shear buckling stresses of CSWs are deduced by the Galerkin method. Simplified formulas for the global shear buckling coefficient $k_{g}$ for a four-edge simple support, for a four-edge fixed support, for two edges constrained by flanges fixed and the other two edges simply supported, and an interactive shear buckling coefficient table are given. Secondly, an elastic finite element analysis is carried out to verify the analytical formulas and to study the influence of geometric parameters on the shear buckling stress of CSWs. Finally, a design formula for the shear strength of CSWs which adopts the formulas for the global and interactive shear buckling stresses proposed in this paper is assessed. From a comparison between the shear strength calculated by this design formula, calculated by four previous design formulas and measured in a series of published test results, it is found that the considered design formula provides good predictions for the shear strength of CSWs and can be recommended.
A R T I C L E H I S T O R Y

$\begin{array}{ll}\text { Received: } & \text { 15 January } 2019 \\ \text { Revised: } & \text { 07 June 2019 } \\ \text { Accepted: } & \text { 13 June 2019 }\end{array}$

\section{K E Y W O R D S}

Corrugated steel web; Global shear buckling; Interactive shear buckling; Shear strength;

Galerkin method;

Finite element analysis

\section{Introduction}

The steel-concrete composite girder with corrugated steel webs (CSWs) (see Fig. 1) is known as a new type of bridge structure to overcome the weight problem of common concrete box girders. Compared with concrete webs, CSWs have low longitudinal stiffness due to the accordion effect, so CSWs mainly carry the shear forces and barely carry axial forces [1]. Because of this characteristic, CSWs fail due to shear buckling or yielding [2]. Therefore, the shear buckling stability of CSWs is one of the most important considerations in the design of this kind of composite girder bridges.

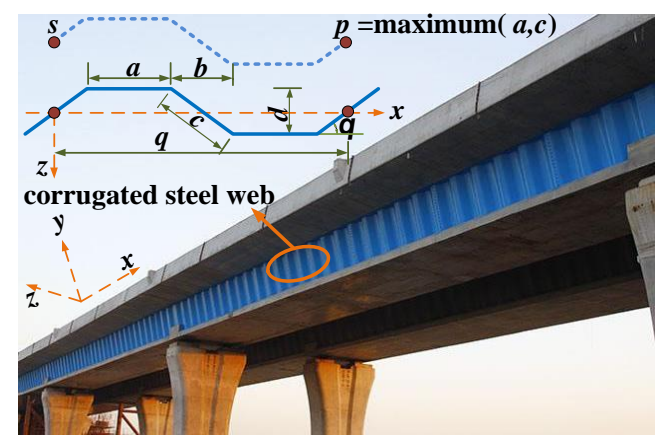

Fig. 1 Composite girder with CSWs

It is widely accepted that local buckling is the primary failure mode in coarse corrugations, whereas global buckling becomes the primary failure mode in dense corrugations and interactive shear buckling mode becomes primary when the density is in between of the two above scenarios [3].

The local shear buckling of CSWs is solved by analyzing a single flat panel constrained by adjacent panels and girder flanges. For this, the shear buckling stress formula of isotropic rectangular plates [4] can be applied. Aggarwal et al. [5] numerically investigated the local shear buckling of CSWs and found that the edge conditions between the CSWs and the girder flanges were close to fixed, while those between the flat and inclined panels lied between simply supported and fixed.

The global shear buckling of CSWs for straight girder bridges is analyzed by treating the whole corrugated steel web (CSW) as an orthotropic rectangular plate constrained by concrete flanges and diaphragms, and has been studied by various researchers. Easley and McFarland [6] investigated the global shear buckling behavior of corrugated metal diaphragms by assuming them as orthotropic plates and developed the formula for the shear buckling load by the Ritz and the Energy method. Then, Easley [7] made a comparative analysis of the Bergmann-Reissner formula [8], the Hlavacek formula [9] and the EasleyMcFarland formula [6], and proposed a more comprehensive and applicable global shear buckling formula of corrugated plates. As application of corrugated plates, initially used for aircrafts, was gradually extended to civil engineering, the formula $\tau_{g}^{e}=k_{g} \frac{\left(D_{x}\right)^{1 / 4}\left(D_{y}\right)^{3 / 4}}{t h^{2}}$ was accepted to calculate the global shear

buckling stress of CSWs, where $k_{g}$ is the global shear buckling coefficient depending on the edge conditions. For a four-edge simple support, Easley [7] suggested $k_{g}=36$, Peterson [10] and Bergfelt et al. [11] suggested $k_{g}=32.4$, while the Guide to Stability Design Criteria for Metal Structures [12] adopts $k_{g}=31.6$. For a four-edge fixed support, Easley [7] suggested $k_{g}=68.4$, Peterson [10] and Bergfelt, et al. [11] suggested $k_{g}=60.4$, while the Guide to Stability Design Criteria for Metal Structures [12] adopts $k_{g}=59.2$. El Metwally and Loov [13] suggested $k_{g}=50$ for composite girders with CSWs. From the studies mentioned above, it is clear that although a global shear buckling formula of CSWs has been proposed, researchers hold different views on the value of the global shear buckling coefficient $k_{g}$. Many adjustments of the coefficient $k_{g}$ are based on FEA only, and lack theoretical support. Machimdamrong et al. [14] presented the transition curves of the elastic global shear buckling capacity with the boundary conditions from a four-edge simple support to a four-edge fixed support using the Rayleigh-Ritz method, but only the curves for the plate dimensions $(l \times h)$ of $1 \mathrm{~m} \times 1 \mathrm{~m}$ and $2 \mathrm{~m} \times 1 \mathrm{~m}$ were provided. Therefore, it is necessary to investigate the global shear buckling of CSWs with different boundary conditions theoretically.

Finally, the formula for the interactive shear buckling is determined by the local and global shear buckling stresses, and the yield stress of the plate material [15], but the way these parameters are to be combined is still the subject of debate. Important work has been done by Bergfelt and Leiva-Aravena [16], El Metwally [17], Abbas et al. [18], Shiratani et al. [19], Sayed-Ahmed [20] and Yi et al. [15], etc., and various interactive shear buckling formulas of CSWs were proposed. All the formulas might be not accurate enough since their forms were too simple [21], and are based on the relationship between the local and global shear buckling stresses, and the yield stress only. All the elastic interactive formulas show that the interactive shear buckling stress is the minimum value of the three shear buckling modes, which is not reasonable and lacks theoretical support. Therefore, it is necessary to investigate the interactive shear buckling of CSWs from a theoretical point of view.

For practical applications, Elgaaly et al. [22] recommended that the 
capacity of CSWs was controlled by the minimum value of local and global buckling stresses, and a semiempirical formula for the inelastic buckling stress was proposed. Driver et al. [23] suggested a lower bound formula by combining local and global shear buckling formulas. Moon et al. [24] proposed a shear buckling parameter formula for trapezoidal CSWs based on the relationship between local, global and interactive shear buckling stresses. Eldib [3] proposed a shear buckling parameter formula for curved CSWs. Nie et al. [21] carried out eight $\mathrm{H}$-shape steel girders with CSWs and suggested a formula for the shear strength prediction of trapezoidal CSWs. Hassanein et al. studied the shear behavior of linearly tapered girder bridges with CSWs [25], and girders with high-strength CSWs [26]. Leblouba and Barakat [2] experimentally and numerically investigated the shear stress distribution in trapezoidal CSWs.

In this study, the whole CSW is treated as an orthotropic plate constrained by flanges and diaphragms for the global shear buckling analysis, and the folded plate composed of two adjacent panels is treated as an isotropic shallow shell for the interactive shear buckling analysis. Firstly, the analytical formulas for the global and interactive shear buckling stresses are derived by the Galerkin method. Then, an elastic finite element analysis (FEA) is carried out to verify the analytical formulas and to study the influence of geometric parameters on the shear buckling stress of CSWs. Finally, a design formula for the shear strength of CSWs which adopts the formulas for the global and interactive shear buckling stresses proposed in this paper is assessed.

\section{Elastic shear buckling stress of CSWs}

\subsection{Physical equivalent parameters of CSWs}

For trapezoidal CSWs that are commonly used in actual girder bridges, when treated as an orthotropic plate, the equivalent flexural stiffnesses $D_{x}, D_{y}$ and the torsional stiffness $D_{x y}$ per unit length of a CSW can be expressed as Eqs. (1)-(3) [6].

$D_{x}=\frac{q}{s} \frac{E t^{3}}{12}=\frac{E t^{3}(2 a+2 d \cdot \cot \theta)}{12(2 a+2 d \cdot \csc \theta)}$

$D_{y}=\frac{E t d^{2}(3 a+c)}{6 q}=\frac{E t d^{2}(3 a+d \cdot \csc \theta)}{6(2 a+2 d \cdot \cot \theta)}$

$D_{x y}=\frac{s}{q} \frac{E t^{3}}{6(1+\mu)}=\frac{E t^{3}(2 a+2 d \cdot \csc \theta)}{6(1+\mu)(2 a+2 d \cdot \cot \theta)}$

where $E$ is the elastic modulus of the original steel plate; $\mu$ is the Poisson's ratio; $t$ is the web thickness. As shown in Fig. 1, $a$ is the flat panel width; $c$ is the inclined panel width; $d$ is the corrugation depth; $\theta$ is the corrugation angle; $q$ is the horizontal projection length of one periodic corrugation; $s$ is the total folded panel length of one periodic corrugation.

\subsection{Elastic local shear buckling}

The shear buckling stress formula of isotropic rectangular plates Eq. (4) [4] can be applied to calculate the elastic local shear buckling stress of CSWs.

$$
\tau_{l}^{e}=k_{l} \frac{\pi^{2} E}{12\left(1-\mu^{2}\right)}\left(\frac{t}{p}\right)^{2}
$$

where $k_{l}$ is the elastic local shear buckling coefficient of CSWs; $p$ is the maximum value of the flat panel width $a$ and the inclined panel width $c$. (7).

The elastic local shear buckling coefficient $k_{l}$ can be expressed as Eqs. (5)-

For a four-edge simple support:

$k_{l, s}=5.34+4(p / h)^{2}$

For a four-edge fixed support:

$k=8.98+5.6(p / h)$ $k_{l, f s}=5.34+2.31(p / h)-3.44(p / h)^{2}+8.39(p / h)^{3}$

\subsection{Elastic global shear buckling}

\subsubsection{Critical buckling stress under pure shear}

A CSW with dense corrugations can be treated as an orthotropic plate (Fig. 2) for the global shear buckling analysis.

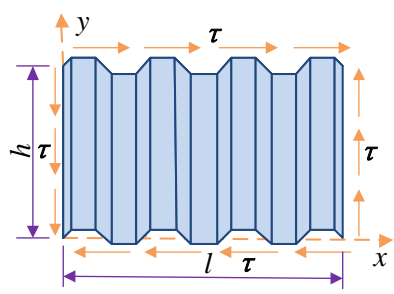

(a) CSW

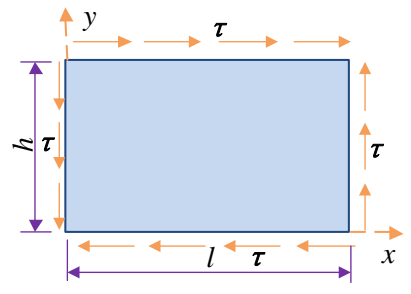

(b) Equivalent orthotropic plate
Fig. $2 \mathrm{CSW}$ and its equivalent orthotropic plate

According to the stability theory of plates, the equilibrium equation of an orthotropic plate subjected to a shear force can be expressed as Eq. (8) [27].

$\frac{1}{t}\left(D_{x} \frac{\partial^{4}}{\partial x^{4}}+D_{x y} \frac{\partial^{4}}{\partial x^{2} \partial y^{2}}+D_{y} \frac{\partial^{4}}{\partial y^{4}}\right) w=2 \tau \frac{\partial^{2} w}{\partial x \partial y}$

where $w$ is the out of plane deflection of the plate, $\tau$ is the shear stress.

It can be assumed that the boundary conditions of CSWs satisfy a fouredge simple support, a four-edge fixed support, or two edges constrained by flanges fixed and the other two edges simply supported (the edges $x=0$ and $x=l$ are simply supported, the edges $y=0$ and $y=h$ are fixed supported). The functions of deflection can be expressed respectively as Eqs. (9)-(11).

For a four-edge simple support [4]:

$w=\sum_{m=1}^{\infty} \sum_{n=1}^{\infty} C_{m n} \sin \frac{m \pi x}{l} \sin \frac{n \pi y}{h}$

For a four-edge fixed support [28]:

$w=\sum_{m=1}^{\infty} \sum_{n=1}^{\infty} C_{m n}\left(\frac{1}{m} \sin \frac{m \pi x}{l}-\frac{1}{m+2} \sin \frac{(m+2) \pi x}{l}\right)\left(\frac{1}{n} \sin \frac{n \pi y}{h}-\frac{1}{n+2} \sin \frac{(n+2) \pi y}{h}\right)$ fixed:

For the edges $x=0$ and $x=l$ simply supported, and the edges $y=0$ and $y=h$

$w=\sum_{m=1}^{\infty} \sum_{n=1}^{\infty} C_{m n} \sin \frac{m \pi x}{l}\left(\frac{1}{n} \sin \frac{n \pi y}{h}-\frac{1}{n+2} \sin \frac{(n+2) \pi y}{h}\right)$

where $h$ is the web height equal to the clear distance between the top and bottom concrete flanges, $l$ is the web length equal to the distance between the two adjacent diaphragm plates.

Given $\lambda=l / h, \alpha=D_{x} / D_{y}$ and $\beta=D_{x y} / D_{y}$, Eq. (8) can be simplified as Eqs. (12)(14) according to the Galerkin method.

For the four-edge simple support:

$\frac{\pi^{4} D_{y}}{4 t h^{2} \lambda^{3}}\left(\alpha m^{4}+\beta m^{2} n^{2} \lambda^{2}+n^{4} \lambda^{4}\right) C_{m n}-8 \tau \sum_{i=1}^{\infty} \sum_{j=1}^{\infty} C_{i j} \frac{m n i j}{\left(m^{2}-i^{2}\right)\left(n^{2}-j^{2}\right)}=0$

( $m \pm i=$ odd number, $n \pm j=$ odd number $)$

For the four-edge fixed support:

For the two edges constrained by flanges fixed and the other two edges simply supported: 


$$
\begin{aligned}
& \frac{D_{y}}{t h^{2}} \frac{\pi^{4}}{4 \lambda^{3}}\left\{\begin{array}{l}
C_{m n}\left\{\begin{array}{l}
\alpha\left[m^{2}+(m+2)^{2}\right]\left[n^{-2}+(n+2)^{-2}\right]+4 \beta \lambda^{2} \\
+\lambda^{4}\left[m^{-2}+(m+2)^{-2}\right]\left[n^{2}+(n+2)^{2}\right]
\end{array}\right\} \\
-C_{m, n+2}\left\{\alpha\left[m^{2}+(m+2)^{2}\right](n+2)^{-2}+2 \beta \lambda^{2}+\lambda^{4}\left[m^{-2}+(m+2)^{-2}\right](n+2)^{2}\right\} \\
-C_{m, n-2}\left\{\alpha\left[m^{2}+(m+2)^{2}\right] n^{-2}+2 \beta \lambda^{2}+\lambda^{4}\left[m^{-2}+(m+2)^{-2}\right] n^{2}\right\} \\
-C_{m+2, n}\left\{\alpha(m+2)^{2}\left[n^{-2}+(n+2)^{-2}\right]+2 \beta \lambda^{2}+\lambda^{4}(m+2)^{-2}\left[n^{2}+(n+2)^{2}\right]\right\} \\
+C_{m+2, n+2}\left[\alpha(m+2)^{2}(n+2)^{-2}+\beta \lambda^{2}+\lambda^{4}(m+2)^{-2}(n+2)^{2}\right] \\
+C_{m+2, n-2}\left[\alpha(m+2)^{2} n^{-2}+\beta \lambda^{2}+\lambda^{4}(m+2)^{-2} n^{2}\right] \\
-C_{m-2, n}\left\{\alpha m^{2}\left[n^{-2}+(n+2)^{-2}\right]+2 \beta \lambda^{2}+\lambda^{4} m^{-2}\left[n^{2}+(n+2)^{2}\right]\right\} \\
+C_{m-2, n+2}\left[\alpha m^{2}(n+2)^{-2}+\beta \lambda^{2}+\lambda^{4} m^{-2}(n+2)^{2}\right] \\
+C_{m-2, n-2}\left[\alpha m^{2} n^{-2}+\beta \lambda^{2}+\lambda^{4} m^{-2} n^{2}\right]
\end{array}\right\} \\
& -8 \tau \sum_{i=1}^{\infty} \sum_{j=1}^{\infty} A_{i j}\left\{\begin{array}{l}
{\left[\frac{1}{m^{2}-i^{2}}-\frac{1}{(m+2)^{2}-i^{2}}-\frac{1}{m^{2}-(i+2)^{2}}+\frac{1}{(m+2)^{2}-(i+2)^{2}}\right]} \\
\times\left[\frac{1}{n^{2}-j^{2}}-\frac{1}{(n+2)^{2}-j^{2}}-\frac{1}{n^{2}-(j+2)^{2}}+\frac{1}{(n+2)^{2}-(j+2)^{2}}\right]
\end{array}\right\}=0
\end{aligned}
$$

( $m \pm i=$ odd number, $n \pm j=$ odd number $)$

For the edges $x=0$ and $x=l$ simply supported, and the edges $y=0$ and $y=h$ fixed:

$$
\begin{aligned}
& \frac{D_{y}}{t h^{2}} \frac{\pi^{4}}{4 \lambda^{3}}\left\{\begin{array}{l}
C_{m n}\left\{\alpha m^{4}\left[n^{-2}+(n+2)^{-2}\right]+2 \beta \lambda^{2} m^{2}+\lambda^{4}\left[n^{2}+(n+2)^{2}\right]\right\} \\
-C_{m, n+2}\left[\alpha m^{4}(n+2)^{-2}+\beta \lambda^{2} m^{2}+\lambda^{4}(n+2)^{2}\right] \\
-C_{m, n-2}\left[\alpha m^{4} n^{-2}+\beta \lambda^{2} m^{2}+\lambda^{4} n^{2}\right]
\end{array}\right\} \\
& -8 \tau \sum_{i=1}^{\infty} \sum_{j=1}^{\infty} A_{i j} \frac{m i}{m^{2}-i^{2}}\left[\begin{array}{l}
\frac{1}{n^{2}-j^{2}}-\frac{1}{(n+2)^{2}-j^{2}}-\frac{1}{n^{2}-(j+2)^{2}} \\
+\frac{1}{(n+2)^{2}-(j+2)^{2}}
\end{array}\right]=0
\end{aligned}
$$

( $m \pm i=$ odd number, $n \pm j=$ odd number)
By assigning values to $m$ and $n$ in Eqs. (12)-(14), a series of linear algebraic equations with $C_{i j}$ as unknowns can be obtained. Then the critical shear buckling stress can be derived by assuming the coefficient determinant of the linear algebraic equations equals zero. (i. e. a linear bifurcation analysis).

According to Eqs. (12)-(14), the elastic global shear buckling stress of CSWs can be expressed as Eq. (15).

$\tau_{g}^{e}=k_{g} \frac{D_{y}}{h^{2} t}$

where $k_{g}$ is the elastic global shear buckling coefficient of CSWs. The detailed solution process of the coefficient $k_{g, s}$ for a four-edge simple support, $k_{g, f}$ for a four-edge fixed support, $k_{g, f s}$ for the edges $x=0$ and $x=l$ simply supported, and the edges $y=0$ and $y=h$ fixed is given below.

\subsubsection{Calculation of the global shear buckling coefficient $k_{g}$}

(1) Comparison with isotropic plate

Based on "Theory of elastic stability" [4], the elastic shear buckling stress of isotropic rectangular plates can be expressed as Eq. (16).

$\tau_{c r}^{e}=k \frac{\pi^{2} D}{h^{2} t}$

where $D$ is the flexural stiffness, and $k$ is the elastic shear buckling coefficient of isotropic rectangular plates. The coefficients $k_{s}$ for the four-edge simple support, $k_{f}$ for the four-edge fixed support, $k_{f s}$ for the edges $x=0$ and $x=l$ simply supported, and the edges $y=0$ and $y=h$ fixed are given in Timoshenko [4].

When $D_{x} / D_{y}=1$ and $D_{x y} / D_{y}=2$, The Eq. (15) for the elastic global shear

\begin{tabular}{|c|c|c|c|c|c|c|c|c|c|c|c|}
\hline \multirow{2}{*}{ Coefficient } & \multirow{2}{*}{ Boundaries } & \multicolumn{10}{|c|}{$l / h$} \\
\hline & & 1 & 1.2 & 1.4 & 1.5 & 1.6 & 1.8 & 2 & 2.5 & 3 & 4 \\
\hline$k_{g, s} / \pi^{2}$ & \multirow{2}{*}{ Four-edge simply } & 9.32 & 7.98 & 7.29 & 7.07 & 6.91 & 6.69 & 6.55 & 6.08 & 5.84 & 5.62 \\
\hline$k_{s}$ & & 9.34 & 8 & 7.3 & 7.1 & 7 & 6.8 & 6.6 & 6.1 & 5.9 & 5.7 \\
\hline$k_{g, f} / \pi^{2}$ & \multirow{2}{*}{ Four-edge fixed } & 15.04 & - & - & 11.77 & - & - & 10.52 & - & - & - \\
\hline$k_{f}$ & & 14.71 & - & - & 11.5 & - & - & 10.34 & - & - & - \\
\hline$k_{g, f} / \pi^{2}$ & $x=0, x=l$ simply & 12.82 & - & - & 11.01 & - & - & 10.26 & 9.88 & 9.73 & - \\
\hline$k_{f s}$ & $y=0, y=h$ fixed & 12.28 & - & - & 11.12 & - & - & 10.21 & 9.81 & 9.61 & - \\
\hline
\end{tabular}
buckling stress of CSWs derived in this paper can be also applied to calculate isotropic plates. The global shear buckling coefficient $k_{g}$ in Eq. (15) should be divided by $\pi^{2}$ to meet the needs of comparison with Timoshenko [4]. The shear buckling coefficient $k$ from Timoshenko [4] and $k_{g} / \pi^{2}$ derived in this paper are

\begin{tabular}{|c|c|c|c|c|c|c|c|c|c|c|c|c|c|c|}
\hline \multirow[t]{2}{*}{ Bridges } & \multirow{2}{*}{$\begin{array}{c}a \\
m m \\
\end{array}$} & \multirow{2}{*}{$\begin{array}{c}b \\
m m\end{array}$} & \multirow{2}{*}{$\begin{array}{c}c \\
m m \\
m\end{array}$} & \multirow{2}{*}{$\begin{array}{c}d \\
m m\end{array}$} & \multirow{2}{*}{$\begin{array}{c}h \\
m m\end{array}$} & \multirow{2}{*}{$\begin{array}{l}t_{\min } \\
\mathrm{mm}\end{array}$} & \multirow{2}{*}{$\begin{array}{l}t_{\max } \\
m m\end{array}$} & \multirow{2}{*}{$\frac{a}{t_{\min }}$} & \multirow{2}{*}{$\frac{a}{t_{\max }}$} & \multirow{2}{*}{$\frac{3 a+c}{q}$} & \multicolumn{2}{|c|}{ Based on $t_{\min }$} & \multicolumn{2}{|c|}{ Based on $t_{\max }$} \\
\hline & & & & & & & & & & & $\alpha$ & $\beta$ & $\alpha$ & $\beta$ \\
\hline Cognac & 353 & 319 & 353 & 150 & 1771 & 8 & 8 & 44.1 & 44.1 & 1.05 & 0.0013 & 0.0022 & 0.0013 & 0.0022 \\
\hline Maupre & 284 & 241 & 284 & 150 & 2650 & 8 & 8 & 35.5 & 35.5 & 1.08 & 0.0012 & 0.0022 & 0.0012 & 0.0022 \\
\hline Dole & 430 & 370 & 430 & 220 & $1800 \sim 4010$ & 8 & 12 & 53.8 & 35.8 & 1.08 & 0.0006 & 0.0010 & 0.0013 & 0.0023 \\
\hline Shinkai & 250 & 200 & 250 & 150 & 1183 & 9 & 9 & 27.8 & 27.8 & 1.11 & 0.0015 & 0.0028 & 0.0015 & 0.0028 \\
\hline Miyukibashi & 300 & 260 & 300 & 150 & 2210 & 8 & 12 & 37.5 & 25.0 & 1.07 & 0.0012 & 0.0022 & 0.0028 & 0.0049 \\
\hline Katsutegawa & 430 & 370 & 430 & 220 & $2080 \sim 5300$ & 9 & 12 & 47.8 & 35.8 & 1.08 & 0.0007 & 0.0013 & 0.0013 & 0.0023 \\
\hline Hondani & 330 & 270 & 336 & 200 & $1025 \sim 5095$ & 9 & 14 & 36.7 & 23.6 & 1.11 & 0.0008 & 0.0016 & 0.0020 & 0.0038 \\
\hline Koinumarukawa & 430 & 370 & 430 & 220 & $1580 \sim 3600$ & 9 & 16 & 47.8 & 26.9 & 1.08 & 0.0007 & 0.0013 & 0.0023 & 0.0041 \\
\hline Shimoda & 430 & 370 & 430 & 220 & $1140 \sim 5360$ & 12 & 16 & 35.8 & 26.9 & 1.08 & 0.0013 & 0.0023 & 0.0023 & 0.0041 \\
\hline Nakano Viaduct & 330 & 270 & 336 & 200 & $1010 \sim 3100$ & 9 & 19 & 36.7 & 17.4 & 1.11 & 0.0008 & 0.0016 & 0.0037 & 0.0070 \\
\hline Kurobekawa Railway & 400 & 350 & 400 & 200 & $2500 \sim 3400$ & 12 & 25 & 33.3 & 16.0 & 1.07 & 0.0016 & 0.0028 & 0.0069 & 0.0120 \\
\hline Altwipfergrund & 360 & 288 & 360 & 220 & $1633 \sim 2674$ & 10 & 22 & 36.0 & 16.4 & 1.11 & 0.0008 & 0.0016 & 0.0041 & 0.0077 \\
\hline Juancheng-Huanghe & 430 & 370 & 430 & 220 & $1729 \sim 4253$ & 10 & 18 & 43.0 & 23.9 & 1.08 & 0.0009 & 0.0016 & 0.0029 & 0.0051 \\
\hline Henan-Pohe & 250 & 200 & 250 & 150 & 1305 & 8 & 8 & 31.3 & 31.3 & 1.11 & 0.0012 & 0.0022 & 0.0012 & 0.0022 \\
\hline Wei River & 330 & 270 & 336 & 200 & $1000 \sim 1350$ & 8 & 12 & 41.3 & 27.5 & 1.11 & 0.0007 & 0.0012 & 0.0015 & 0.0028 \\
\hline Nanjing-Chuhe & 430 & 370 & 430 & 220 & $2420 \sim 4900$ & 10 & 18 & 43.0 & 23.9 & 1.08 & 0.0009 & 0.0016 & 0.0029 & 0.0051 \\
\hline
\end{tabular}
given in Table 1.

As can be seen from Table 1 , the average difference between $k_{g} / \pi^{2}$ derived in this paper, which takes 900 trigonometric series $(m=30, n=30)$, and $k$ from Timoshenko [4] is $1.2 \%$ (the maximum being $4.4 \%$ ) showing the accuracy of the solution method proposed in this paper.

Table 1

Elastic shear buckling coefficient of isotropic rectangular plates

Note: "- " expresses the value of $k$ is not given in Timoshenko [4].

Table 2

Geometry of CSWs in actual bridges [3, 15, 24, 26, 29]

Note: $t_{\max }$ and $t_{\min }$ are the maximum and minimum thicknesses of CSWs respectively when an actual bridge has more than one thickness value. 
(2) Calculation of $k_{g}$

According to Eqs. (12)-(15), the global shear buckling coefficient $k_{g}$ is associated with the length to height ratio $\lambda(l / h)$, and the rigidity ratios $\alpha\left(D_{x} / D_{y}\right)$ and $\beta\left(D_{x y} / D_{y}\right)$. A statistical analysis of available bridges with CSWs (as shown in Table 2) shows that the rigidity ratio $\alpha$ varies from 0.0006 to 0.0069 , whereas $\beta$ is about (1.67 2.0) $\alpha$. The following parametric study considers $\alpha$ ranging from 0.0005 to 0.0070 , and $\beta$ equal to $1.6 \alpha, 1.8 \alpha, 2.0 \alpha$ respectively.

Theoretically, the more numbers used in the trigonometric series (as shown in Eqs. (9)-(11)), the more precise the solution is. If $m$ and $n$ increase toward infinity, exact results of shear buckling stress can be obtained. However, the calculation effort increases with the increasing numbers $m$ and $n$ in the trigonometric series. In the case of the $\mathrm{CSW}$ with a length to height ratio $l / h$ less than 5, the deviation between the results with $m=30, n=30$ and the results with $m=25, n=25$ is less than $1 \%$. So, adopting $m=30$ and $n=30$ for further calculation will not only ensure the accuracy of the calculation but also reduce the calculation effort.

Table 3 shows the values of $k_{g, s}$ calculated for various values of $D_{x} / D_{y}$ and $l / h$, and for $\beta=1.6 \alpha, \beta=1.8 \alpha$ and $\beta=2.0 \alpha$ respectively for a four-edge simple support. The results for $\beta=1.6 \alpha$ and $\beta=2.0 \alpha$, compared to for $\beta=1.8 \alpha$, deviate less than $0.6 \%$. The results show that the parameter $\beta / \alpha$ has little effect on the coefficient $k_{g}$ for common bridges with CSWs. From an engineering application point of view, the deviations can be ignored. In addition, the conclusion remains unchanged for a four-edge fixed support, and for two edges constrained by flanges fixed and the other two edges simply supported. As a result, $\beta=1.8 \alpha$ is used further in this paper.

Tables 4-6 list the values of the global shear buckling coefficient $k_{g}$ for length to height ratios $l / h$ varying from 1 to 5 , a rigidity ratio $D_{x} / D_{y}$ varying from 0.0005 to 0.0070 , and a fixed value of $\beta=1.8 \alpha$. As shown in Tables 4 to 6 , global shear buckling coefficients $k_{g, s}, k_{g, f}$, and $k_{g, f s}$ for an equal web length to height ratio $l / h$ and rigidity ratio $D_{x} / D_{y}$ exhibit relationships: $k_{g, f} / k_{g, s}=1.84 \sim 1.90$, $k_{g, f} / k_{g, s}=1.83 \sim 1.89, k_{g, f} / k_{g, f s}=1 \sim 1.013$. This shows that the global shear buckling stress for the four-edge fixed support is only slightly higher than for two edges constrained by flanges fixed and the other two edges simply supported, the difference is less than $1.5 \%$.

Table 3

The effect of $\beta / \alpha$ on the global shear buckling coefficient $k_{g, s}$ for the four-edge simple support

\begin{tabular}{|c|c|c|c|c|c|c|}
\hline \multirow[t]{2}{*}{$D_{x} / D_{y}$} & & \multicolumn{5}{|c|}{$l / h$} \\
\hline & & 1 & 2 & 3 & 4 & 5 \\
\hline \multirow{3}{*}{0.0005} & $\beta=1.6 \alpha$ & 5.016 & 4.947 & 4.933 & 4.929 & 4.927 \\
\hline & $\beta=1.8 \alpha$ & 5.024 & 4.954 & 4.940 & 4.936 & 4.934 \\
\hline & $\beta=2.0 \alpha$ & 5.031 & 4.962 & 4.948 & 4.944 & 4.942 \\
\hline \multirow{3}{*}{0.0015} & $\beta=1.6 \alpha$ & 6.729 & 6.593 & 6.562 & 6.550 & 6.545 \\
\hline & $\beta=1.8 \alpha$ & 6.747 & 6.610 & 6.579 & 6.567 & 6.562 \\
\hline & $\beta=2.0 \alpha$ & 6.765 & 6.627 & 6.597 & 6.585 & 6.579 \\
\hline \multirow{3}{*}{0.0025} & $\beta=1.6 \alpha$ & 7.741 & 7.561 & 7.509 & 7.492 & 7.485 \\
\hline & $\beta=1.8 \alpha$ & 7.767 & 7.586 & 7.534 & 7.517 & 7.510 \\
\hline & $\beta=2.0 \alpha$ & 7.793 & 7.611 & 7.559 & 7.542 & 7.535 \\
\hline \multirow{3}{*}{0.0035} & $\beta=1.6 \alpha$ & 8.508 & 8.269 & 8.215 & 8.195 & 8.185 \\
\hline & $\beta=1.8 \alpha$ & 8.543 & 8.302 & 8.248 & 8.227 & 8.217 \\
\hline & $\beta=2.0 \alpha$ & 8.577 & 8.335 & 8.280 & 8.259 & 8.249 \\
\hline \multirow{3}{*}{0.0050} & $\beta=1.6 \alpha$ & 9.526 & 9.113 & 9.047 & 9.020 & 9.006 \\
\hline & $\beta=1.8 \alpha$ & 9.568 & 9.155 & 9.090 & 9.062 & 9.048 \\
\hline & $\beta=2.0 \alpha$ & 9.610 & 9.198 & 9.132 & 9.104 & 9.090 \\
\hline \multirow{3}{*}{0.0070} & $\beta=1.6 \alpha$ & 10.392 & 10.031 & 9.919 & 9.885 & 9.870 \\
\hline & $\beta=1.8 \alpha$ & 10.449 & 10.085 & 9.973 & 9.939 & 9.924 \\
\hline & $\beta=2.0 \alpha$ & 10.507 & 10.139 & 10.028 & 9.993 & 9.977 \\
\hline
\end{tabular}

Table 4

Global shear buckling coefficient $k_{g, s}$ for a four-edge simple support

\begin{tabular}{|c|c|c|c|c|c|c|c|c|c|c|c|c|}
\hline \multirow{2}{*}{$l / h$} & \multicolumn{12}{|c|}{$D_{x} / D_{y}$} \\
\hline & 0.0005 & 0.001 & 0.0015 & 0.002 & 0.0025 & 0.003 & 0.0035 & 0.004 & 0.0045 & 0.005 & 0.006 & 0.007 \\
\hline 1 & 5.024 & 6.047 & 6.747 & 7.335 & 7.767 & 8.165 & 8.543 & 8.903 & 9.249 & 9.568 & 10.025 & 10.449 \\
\hline 1.5 & 4.975 & 5.964 & 6.647 & 7.186 & 7.639 & 8.017 & 8.371 & 8.705 & 9.002 & 9.255 & 9.728 & 10.172 \\
\hline 2 & 4.954 & 5.937 & 6.610 & 7.134 & 7.586 & 7.958 & 8.302 & 8.624 & 8.899 & 9.155 & 9.638 & 10.085 \\
\hline 2.5 & 4.945 & 5.924 & 6.589 & 7.113 & 7.552 & 7.929 & 8.268 & 8.579 & 8.853 & 9.112 & 9.596 & 10.005 \\
\hline 3 & 4.940 & 5.914 & 6.579 & 7.100 & 7.534 & 7.911 & 8.248 & 8.553 & 8.829 & 9.090 & 9.556 & 9.973 \\
\hline 4 & 4.936 & 5.906 & 6.567 & 7.085 & 7.517 & 7.893 & 8.227 & 8.528 & 8.806 & 9.062 & 9.527 & 9.939 \\
\hline 5 & 4.932 & 5.903 & 6.562 & 7.079 & 7.510 & 7.884 & 8.217 & 8.517 & 8.794 & 9.048 & 9.510 & 9.924 \\
\hline
\end{tabular}

Table 5

Global shear buckling coefficient $k_{g, f}$ for a four-edge fixed support

\begin{tabular}{|c|c|c|c|c|c|c|c|c|c|c|c|c|}
\hline \multirow{2}{*}{$l / h$} & & \multicolumn{11}{|c|}{$D_{x} / D_{y}$} \\
\hline & 0.0005 & 0.001 & 0.0015 & 0.002 & 0.0025 & 0.003 & 0.0035 & 0.004 & 0.0045 & 0.005 & 0.006 & 0.007 \\
\hline 1 & 9.454 & 11.352 & 12.654 & 13.666 & 14.533 & 15.297 & 15.946 & 16.546 & 17.109 & 17.642 & 18.616 & 19.428 \\
\hline 1.5 & 9.392 & 11.242 & 12.502 & 13.494 & 14.314 & 15.039 & 15.669 & 16.247 & 16.785 & 17.273 & 18.153 & 18.954 \\
\hline 2 & 9.370 & 11.204 & 12.451 & 13.427 & 14.240 & 14.950 & 15.573 & 16.143 & 16.662 & 17.140 & 18.016 & 18.784 \\
\hline 2.5 & 9.360 & 11.187 & 12.428 & 13.397 & 14.207 & 14.909 & 15.529 & 16.093 & 16.606 & 17.083 & 17.942 & 18.712 \\
\hline 3 & 9.357 & 11.178 & 12.415 & 13.382 & 14.188 & 14.887 & 15.505 & 16.065 & 16.577 & 17.051 & 17.908 & 18.668 \\
\hline 4 & 9.354 & 11.170 & 12.409 & 13.368 & 14.171 & 14.865 & 15.482 & 16.039 & 16.548 & 17.020 & 17.871 & 18.628 \\
\hline 5 & 9.352 & 11.165 & 12.402 & 13.359 & 14.163 & 14.856 & 15.473 & 16.029 & 16.538 & 17.007 & 17.856 & 18.610 \\
\hline
\end{tabular}


Table 6

Global shear buckling coefficient $k_{g, f s}$ for two edges constrained by flanges fixed and the other two edges simply supported

\begin{tabular}{|c|c|c|c|c|c|c|c|c|c|c|c|c|}
\hline \multirow{2}{*}{$l / h$} & & \multicolumn{11}{|c|}{$D_{x} / D_{y}$} \\
\hline & 0.0005 & 0.001 & 0.0015 & 0.002 & 0.0025 & 0.003 & 0.0035 & 0.004 & 0.0045 & 0.005 & 0.006 & 0.007 \\
\hline 1 & 9.442 & 11.308 & 12.590 & 13.614 & 14.447 & 15.170 & 15.841 & 16.469 & 16.989 & 17.470 & 18.371 & 19.214 \\
\hline 1.5 & 9.386 & 11.227 & 12.483 & 13.464 & 14.296 & 14.996 & 15.636 & 16.212 & 16.725 & 17.210 & 18.113 & 18.878 \\
\hline 2 & 9.366 & 11.198 & 12.445 & 13.419 & 14.229 & 14.930 & 15.558 & 16.121 & 16.636 & 17.121 & 17.979 & 18.753 \\
\hline 2.5 & 9.359 & 11.183 & 12.423 & 13.391 & 14.199 & 14.898 & 15.521 & 16.080 & 16.595 & 17.070 & 17.928 & 18.691 \\
\hline 3 & 9.356 & 11.176 & 12.413 & 13.378 & 14.183 & 14.881 & 15.500 & 16.057 & 16.571 & 17.041 & 17.897 & 18.658 \\
\hline 4 & 9.353 & 11.168 & 12.408 & 13.368 & 14.170 & 14.863 & 15.479 & 16.036 & 16.545 & 17.016 & 17.866 & 18.623 \\
\hline 5 & 9.351 & 11.164 & 12.401 & 13.358 & 14.162 & 14.855 & 15.472 & 16.028 & 16.537 & 17.006 & 17.854 & 18.607 \\
\hline
\end{tabular}

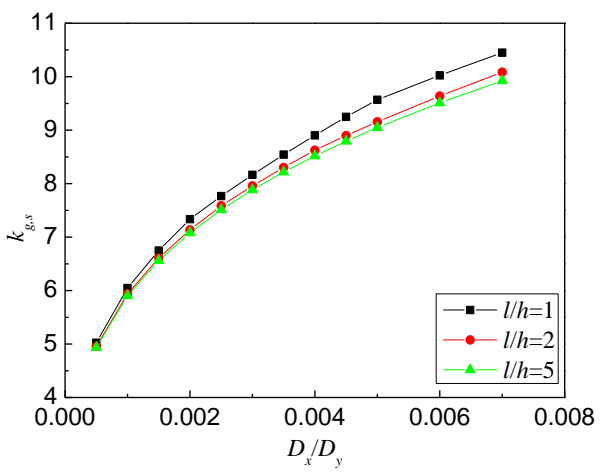

(a) Four-edge simply support
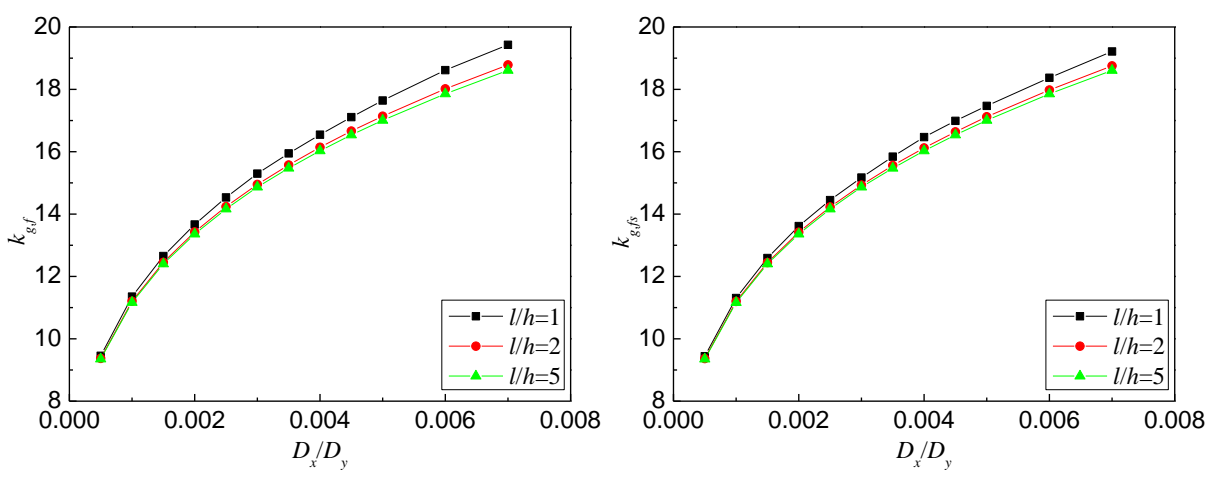

$\begin{array}{ll}\text { (b) Four-edge fixed support } & \text { (c) Two edges constrained by flanges fixed and the other two edges simply supported }\end{array}$

Fig. 3 The effect of the rigidity ratio $D_{x} / D_{y}$ on the global shear buckling coefficient $k_{g}$

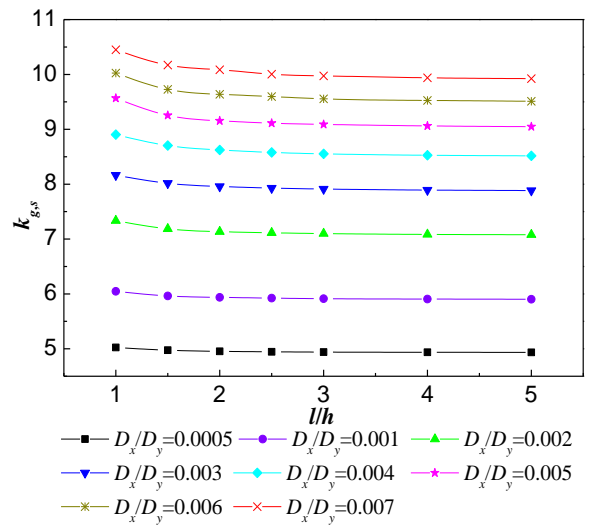

(a) Four-edge simply support
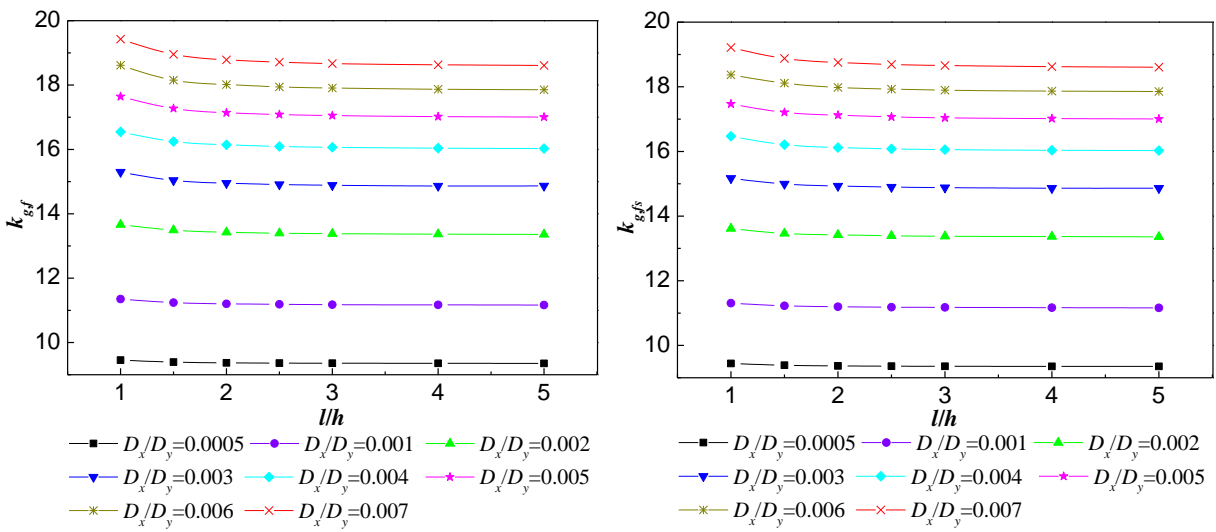

$\begin{array}{lll}\text { (b) Four-edge fixed support } & \text { (c) Two edges constrained by flanges fixed and the other two edges simply supported }\end{array}$

Fig. 4 The effect of the length to height ratio $l / h$ on the global shear buckling coefficient $k_{g}$

Table 7

Values of the global shear buckling coefficient $k_{g}$ for $l / h=5$

\begin{tabular}{|c|c|c|c|c|c|c|c|c|c|c|c|c|c|c|}
\hline \multirow{2}{*}{$k_{g}$} & \multicolumn{14}{|c|}{$D_{x} / D_{y}$} \\
\hline & 0.0005 & 0.001 & 0.0015 & 0.002 & 0.0025 & 0.003 & 0.0035 & 0.004 & 0.0045 & 0.005 & 0.0055 & 0.006 & 0.0065 & 0.007 \\
\hline$k_{g, s}$ & 4.932 & 5.903 & 6.562 & 7.079 & 7.510 & 7.884 & 8.217 & 8.517 & 8.794 & 9.048 & 9.288 & 9.510 & 9.722 & 9.924 \\
\hline$k_{g, f}$ & 9.352 & 11.165 & 12.402 & 13.359 & 14.163 & 14.856 & 15.473 & 16.029 & 16.538 & 17.007 & 17.444 & 17.856 & 18.242 & 18.610 \\
\hline$k_{g, f s}$ & 9.351 & 11.164 & 12.401 & 13.358 & 14.162 & 14.855 & 15.472 & 16.028 & 16.537 & 17.006 & 17.443 & 17.854 & 18.240 & 18.607 \\
\hline
\end{tabular}

(3) The effect of the rigidity ratio $D_{x} / D_{y}$ and the length to height ratio $l / h$ on the global shear buckling coefficient $k_{g}$

According to the values of $k_{g}$ given in Tables 4 to 6 , for common bridges with CSWs, Figs. 3-4 show the effect of the web rigidity ratio $D_{x} / D_{y}$ and the length to height ratio $l / h$ on the global shear buckling coefficient $k_{g}$. As we can see from Figs. 3-4, the global shear buckling coefficient $k_{g}$ increases with the increase of the rigidity ratio $D_{x} / D_{y}$, and decreases with the increase of the length to height ratio $l / h$ but only very little. When $l / h$ is larger than 2 , which is common for CSW bridges, the change of $k_{g}$ is minimal and the values of $k_{g}$ show a converging trend.
2.3.3. Elastic global shear buckling stress of CSWs

Substituting Eq. (2) into Eq. (15), the elastic global shear buckling stress of CSWs can be expressed as Eq. (17).

$\tau_{g}^{e}=k_{g} \frac{E(3 a+c) d^{2}}{6 q h^{2}}=k_{g} \frac{E d^{2}(3 a+d \cdot \csc \theta)}{6 h^{2}(2 a+2 d \cdot \cot \theta)}$

Because the values of $k_{g}$ show a converging trend when $l / h$ is larger than 2, we assume $l / h=5$ for further calculation. This will not only ensure the accuracy of the calculation but also meet the engineering requirements of design simplicity. Table 7 lists the values of $k_{g}$ for $l / h=5$. 
Through fitting of the data in Table 7, for CSWs with $0.0005 \leqslant \alpha \leqslant 0.0070$, the global shear buckling coefficients $k_{g, s}, k_{g, f}$, and $k_{g, f s}$ can be estimated respectively as Eqs. (18) and (19).

For a four-edge simple support:

$$
k_{g, s}=36.8 \alpha^{0.2648}
$$

For a four-edge fixed support, or for two edges constrained by flanges fixed and the other two edges simply supported:

$$
k_{g, f}=k_{g, f s}=67.7 \alpha^{0.2608}
$$

For trapezoidal CSWs that are commonly used in actual bridges, the rigidity ratio $\alpha$ can be expressed as Eq. (20).

$$
\alpha=\frac{D_{x}}{D_{y}}=\frac{q^{2} t^{2}}{2 s(3 a+c) d^{2}}=\left(\frac{t}{d}\right)^{2} \frac{(2 a+2 d \cdot \cot \theta)^{2}}{2(2 a+2 d \cdot \csc \theta)(3 a+d \cdot \csc \theta)}
$$

\subsection{Elastic interactive shear buckling}

\subsubsection{Critical buckling stress under pure shear}

For the interactive shear buckling analysis, folded plate theory is used. A folded plate structure is a spatial thin wall system with several long and thin plates intersecting. Since interactive shear buckling represents the buckling of a few panels, several panels of CSWs can be treated as a folded plate. For simplicity, the folded plate composed of two adjacent panels shown in Fig. 5 is studied here. According to the theory of thin plates and shells, if $l_{3} / l_{*} \leq 0.2$, the folded plate can be analyzed as a shallow shell. CSWs general meet this condition.

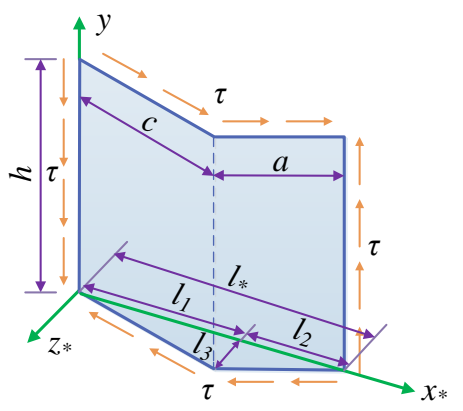

Fig. 5 Shear transfer of interactive shear buckling

In the coordinate system as shown in Fig. 5, the equation for the surface of the shell can be expressed as Eq. (21).

$z=\frac{l_{3}}{l_{1}} x\left[1-u\left(x-l_{1}\right)\right]+\frac{l_{3}}{l_{2}}\left[\left(l_{1}+l_{2}\right)-x\right] u\left(x-l_{1}\right)$

where $u\left(x-l_{1}\right)$ is the step function and can be expressed as $u\left(x-l_{1}\right)=\left\{\begin{array}{ll}0 & x<l_{1} \\ 1 & x \geq l_{1}\end{array}\right.$.

The equilibrium equation and the deformation compatibility equation of a shallow shell under pure shear force can be expressed respectively as Eqs. (22) and (23) [30].

$\frac{D}{t} \nabla^{4} f+\left(k_{x} \frac{\partial^{2}}{\partial y^{2}}-2 k_{x y} \frac{\partial^{2}}{\partial x \partial y}+k_{y} \frac{\partial^{2}}{\partial x^{2}}\right) \Phi=2 \tau \frac{\partial^{2} f}{\partial x \partial y}$

$\frac{1}{E} \nabla^{4} \Phi-\left(k_{x} \frac{\partial^{2}}{\partial y^{2}}-2 k_{x y} \frac{\partial^{2}}{\partial x \partial y}+k_{y} \frac{\partial^{2}}{\partial x^{2}}\right) f=0$

where $f$ is the out of plane deflection of the shell, $\Phi$ is the stress function, $k_{x}=-\frac{\partial^{2} z}{\partial x^{2}}, k_{y}=-\frac{\partial^{2} z}{\partial y^{2}}, k_{x y}=-\frac{\partial^{2} z}{\partial x \partial y}$.

It can be conservatively assumed that the boundary conditions of CSWs for the interactive shear buckling analysis satisfy four-edge simple support. The deflection function and stress function can be expressed respectively as Eqs. (24) and (25).

$f=\sum_{m=1}^{\infty} \sum_{n=1}^{\infty} A_{m n} \sin \frac{m \pi x}{l_{*}} \sin \frac{n \pi y}{h}$

$\Phi=\sum_{m=1}^{\infty} \sum_{n=1}^{\infty} B_{m n} \sin \frac{m \pi x}{l_{*}} \sin \frac{n \pi y}{h}$

According to the Galerkin method and give $\eta=h / l_{*}$, Eqs. (24) and (25) can be simplified as Eqs. (26) and (27) respectively.

$A_{i j} \frac{D \pi^{4}}{4 t \eta^{3} l_{*}^{2}}\left(\eta^{2} i^{2}+j^{2}\right)^{2}+\frac{\pi^{2} l_{3}\left(l_{1}+l_{2}\right)}{2 \eta l_{*} l_{1} l_{2}} j^{2} \sin \frac{i \pi l_{1}}{l_{*}} \sum_{p=1}^{\infty} B_{p j} \sin \frac{p \pi l_{1}}{l_{*}}$

$-8 \tau \sum_{m=1}^{\infty} \sum_{n=1}^{\infty} A_{m n} \frac{m n i j}{\left(i^{2}-m^{2}\right)\left(j^{2}-n^{2}\right)}=0$

( $m \pm i=$ odd,$n \pm j=$ odd $)$

$B_{i j} \frac{\pi^{4}}{4 E \eta^{3} l_{*}^{2}}\left(\eta^{2} i^{2}+j^{2}\right)^{2}-\frac{\pi^{2} l_{3}\left(l_{1}+l_{2}\right)}{2 \eta l_{*} l_{1} l_{2}} j^{2} \sin \frac{i \pi l_{1}}{l_{*}} \sum_{m=1}^{\infty} A_{m j} \sin \frac{m \pi l_{1}}{l_{*}}=0$

Make $\gamma=l_{1} / l_{*}$, then $l_{1}=\gamma l_{*}, \quad l_{2}=(1-\gamma) l_{*}, \quad l_{3}^{2}=c^{2}-\gamma^{2} l_{*}^{2}$. By substituting Eq. (27) to Eq. (26), Eq. (26) can be simplified as Eq. (28).

$$
\begin{aligned}
& A_{i j} \frac{\pi^{4}}{4 \eta^{3}} \frac{D}{t l_{*}^{2}}\left(\eta^{2} i^{2}+j^{2}\right)^{2} \\
& +12 \eta j^{4}\left(1-u^{2}\right) \frac{D}{t l_{*}^{2}} \frac{\left(c^{2}-\gamma^{2} l_{*}^{2}\right)}{t^{2} \gamma^{2}(1-\gamma)^{2}} \sin i \gamma \pi \sum_{p=1}^{\infty} \frac{(\sin p \gamma \pi)^{2}}{\left(\eta^{2} p^{2}+j^{2}\right)^{2}} \sum_{q=1}^{\infty} A_{q j} \sin q \gamma \pi \\
& -8 \tau \sum_{m=1}^{\infty} \sum_{n=1}^{\infty} A_{m n} \frac{m n i j}{\left(i^{2}-m^{2}\right)\left(j^{2}-n^{2}\right)}=0 \\
& (m \pm i=\text { odd }, n \pm j=\text { odd })
\end{aligned}
$$

Table 2 shows that the flat panel width $a$ is almost equal to the inclined panel width $c$ for actual bridges with CSWs. Sayed-Ahmed [20] also proposed $a=c$. When $a=c$, then $l_{1}=l_{2}=0.5 l_{*}, \quad l_{3}=a \sin (\theta / 2)$. Eq. (28) can be simplified as Eq. (29).

$$
\begin{aligned}
& A_{i j} \frac{D}{t l_{*}^{2}} \frac{\pi^{4}}{4 \eta^{3}}\left(\eta^{2} i^{2}+j^{2}\right)^{2} \\
& +192 \eta j^{4}\left(1-u^{2}\right) \sin \frac{i \pi}{2} \frac{D}{t l_{*}^{2}}\left(\frac{a}{t} \sin \frac{\theta}{2}\right)^{2} \sum_{p=1}^{\infty} \frac{\left(\sin \frac{p \pi}{2}\right)^{2}}{\left(\lambda^{2} p^{2}+j^{2}\right)^{2}} \sum_{q=1}^{\infty} A_{q j} \sin \frac{q \pi}{2} \\
& -8 \tau \sum_{m=1}^{\infty} \sum_{n=1}^{\infty} A_{m n} \frac{m n i j}{\left(i^{2}-m^{2}\right)\left(j^{2}-n^{2}\right)}=0 \\
& (m \pm i=\text { odd }, n \pm j=\text { odd })
\end{aligned}
$$

By assigning values to $i$ and $j$ in Eq. (28) or (29), a series of linear algebraic equations with $A_{m n}$ as unknowns can be obtained. Then the critical shear buckling stress can be derived by assuming the coefficient determinant of the linear algebraic equations equals zero. (i. e. a linear bifurcation analysis)

According to Eq. (28), the elastic interactive shear buckling stress of CSWs can be expressed as Eq. (30). 
$\tau_{i}^{e}=k_{i} \frac{D}{l_{*}^{2} t}$

For CSWs with $a=c$, Eq. (30) can be expressed as Eq. (31).

$$
\tau_{i}^{e}=k_{i} \frac{E t^{2}}{12\left(1-\mu^{2}\right)(2 a \cos (\theta / 2))^{2}}
$$

where $k_{i}$ is the elastic interactive shear buckling coefficient of CSWs. The detailed solution process of the coefficient $k_{i}$ is given below.

\subsubsection{Calculation of the interactive shear buckling coefficient $k_{i}$}

According to Eq. (28) and using some mathematical softwares, the interactive shear buckling coefficient $k_{i}$ can be calculated easily. According to
Eq. (29), the coefficient $k_{i}$ for CSWs with $a=c$ is associated with the aspect ratio $h / l_{*}$ and the parameter $\frac{a}{t} \sin \frac{\theta}{2}$.

Table 2 shows that the parameter alt varies from 16 to 54. For CSWs used in actual bridges, values of $\theta$ between $30^{\circ}$ and $45^{\circ}$ are typical [31], so the parameter $\frac{a}{t} \sin \frac{\theta}{2}$ normally varies from 4 to 21 . Table 8 shows the values of $k_{i}$ in the case of $h / l_{*} \leq 6$ and $0 \leq \frac{a}{t} \sin \frac{\theta}{2} \leq 30$. The coefficient $k_{i}$ for CSWs with $a=c$ can be calculated by linear interpolation

Table 8

The interactive shear buckling coefficient of CSWs $k_{i}$

\begin{tabular}{|c|c|c|c|c|c|c|c|}
\hline$a \sin (\theta / 2) / t$ & 1 & 1.5 & 2 & 2.5 & 3 & 4 & 6 \\
\hline 0 & 92.0294 & 69.7779 & 64.6068 & 59.5429 & 57.6401 & 55.5123 & 54.0737 \\
\hline 0.25 & 93.1769 & 70.4358 & 65.1533 & 60.1504 & 58.2841 & 56.2034 & 54.7502 \\
\hline 0.5 & 96.4737 & 72.3623 & 66.7412 & 61.6682 & 59.7653 & 57.7165 & 56.2556 \\
\hline 0.75 & 101.5418 & 75.4292 & 69.2377 & 64.1539 & 62.2492 & 60.0918 & 58.6002 \\
\hline 1 & 107.9047 & 79.4587 & 72.4772 & 67.3685 & 65.4597 & 63.3175 & 61.8178 \\
\hline 1.25 & 115.1066 & 84.2573 & 76.3023 & 71.1993 & 69.2471 & 67.1066 & 65.6054 \\
\hline 1.5 & 122.7766 & 89.6403 & 80.5822 & 75.4736 & 73.5211 & 71.3398 & 69.8362 \\
\hline 1.75 & 130.6405 & 95.4438 & 85.2126 & 80.0664 & 78.1059 & 75.9049 & 74.4034 \\
\hline 2 & 138.5077 & 101.529 & 90.1107 & 85.0094 & 83.0432 & 80.8299 & 79.3286 \\
\hline 2.25 & 146.2490 & 107.7805 & 95.2084 & 90.1018 & 88.1264 & 85.8974 & 84.3952 \\
\hline 2.5 & 153.7778 & 114.1043 & 100.4489 & 95.3454 & 93.3434 & 91.1428 & 89.6401 \\
\hline 2.75 & 161.0361 & 120.4235 & 105.7836 & 100.2358 & 98.1972 & 96.0022 & 94.5007 \\
\hline 3 & 167.9851 & 126.6760 & 111.1704 & 104.6219 & 102.5653 & 100.3454 & 98.6773 \\
\hline 3.25 & 174.5993 & 132.8113 & 116.5728 & 109.0573 & 106.9074 & 104.6971 & 102.0138 \\
\hline 3.5 & 180.8631 & 138.7891 & 121.9590 & 113.5325 & 110.5256 & 108.2896 & 105.3762 \\
\hline 3.75 & 186.7687 & 144.5771 & 127.3010 & 118.0361 & 114.1704 & 111.9992 & 108.7868 \\
\hline 4 & 192.3144 & 150.1502 & 132.5740 & 122.5558 & 117.8456 & 115.6795 & 112.2527 \\
\hline 4.25 & 197.5036 & 155.4890 & 137.7565 & 127.0794 & 121.5508 & 119.3297 & 115.7745 \\
\hline 4.5 & 202.3438 & 160.5796 & 142.8289 & 131.5948 & 125.2828 & 123.0553 & 119.3492 \\
\hline 4.75 & 206.8458 & 165.4126 & 147.7743 & 136.0904 & 129.0371 & 126.7668 & 122.9721 \\
\hline 5 & 211.0229 & 169.9825 & 152.5772 & 140.5553 & 132.8082 & 129.9071 & 126.6377 \\
\hline 5.5 & 218.4650 & 178.3284 & 161.7019 & 149.3521 & 140.3772 & 135.0183 & 132.0734 \\
\hline 6 & 224.8047 & 185.6367 & 170.1093 & 157.9097 & 147.9408 & 140.2147 & 137.4093 \\
\hline 6.5 & 230.1828 & 191.9637 & 177.7254 & 166.1610 & 155.4507 & 145.4974 & 142.7003 \\
\hline 7 & 234.7358 & 197.3909 & 184.4964 & 174.0451 & 162.8600 & 150.8560 & 148.1038 \\
\hline 7.5 & 238.5894 & 202.0147 & 190.3940 & 181.5032 & 170.1220 & 156.2740 & 153.4890 \\
\hline 8 & 241.8551 & 205.9366 & 195.4237 & 188.4706 & 177.1872 & 161.7319 & 159.0231 \\
\hline 9 & 246.9941 & 212.0662 & 203.1006 & 197.9587 & 190.4379 & 172.6793 & 169.9498 \\
\hline 10 & 249.6481 & 216.4745 & 208.2566 & 203.1951 & 196.9761 & 183.4995 & 178.9182 \\
\hline 12 & 252.7794 & 222.0752 & 214.1494 & 209.0746 & 203.8849 & 193.4008 & 190.8814 \\
\hline 14 & 254.6094 & 225.2856 & 217.2037 & 212.2282 & 208.4515 & 204.5305 & 202.8039 \\
\hline 16 & 255.7683 & 227.2733 & 219.0022 & 214.6838 & 211.9712 & 209.8780 & 208.0037 \\
\hline 18 & 256.5482 & 228.5854 & 220.1599 & 215.6484 & 212.9664 & 210.7748 & 209.0133 \\
\hline 20 & 257.0984 & 229.4967 & 220.9213 & 216.3216 & 213.6575 & 211.4042 & 209.6595 \\
\hline 22 & 257.5011 & 230.1558 & 221.4389 & 216.8106 & 214.1583 & 211.8635 & 210.0977 \\
\hline 24 & 257.805 & 230.6483 & 221.8279 & 217.1773 & 214.5333 & 212.2091 & 210.4349 \\
\hline 26 & 258.0399 & 231.0262 & 222.1278 & 217.4597 & 214.8217 & 212.4759 & 210.6952 \\
\hline 28 & 258.2253 & 231.3226 & 222.3639 & 217.6818 & 215.0485 & 212.6861 & 210.9005 \\
\hline 30 & 258.3743 & 231.5596 & 222.5532 & 217.8598 & 215.2300 & 212.8548 & 211.0652 \\
\hline
\end{tabular}




\subsection{Discussion of the local, global and interactive shear buckling stresses}

Three shear buckling modes are discussed theoretically in this paper. Local buckling is the buckling of a panel and solved by analyzing a single flat panel under shear force, whereas global buckling is the buckling of the whole CSW and solved by treating the whole CSW as an orthotropic plate. Interactive buckling is the buckling of 2 4 panels and solved by treating the 2 4 panels as a folded plate.

Theoretically, the local shear buckling stress $\tau_{l}^{e}$ is associated with $t / p, p / h$ which can be seen from Eqs. (4)-(7), whereas the global shear buckling stress $\tau_{g}^{e}$ is associated with $\theta, d / h$ and $t / d$ which can be seen from Eqs. (17)-(20). The interactive shear buckling stress $\tau_{i}^{e}$ is associated with the geometric dimensioning of CSWs which can be seen from Eqs. (28)-(31). When CSWs have equal $d / t, p / h$ and $\theta$ values, they will have an equal $t / p$ ratio which affects the local shear buckling stress $\tau_{l}^{e}$, and equal $d / h$ and $t / d$ ratios which affect the global shear buckling stress $\tau_{g}^{e}$. In the case of $a=c$, they will have an equal $\eta=h /(2 a \cos (\theta / 2))$ and $t /(a \cos (\theta / 2))$ which affect the interactive shear buckling stress $\tau_{i}^{e}$. For CSWs with equal $d / t, a / h$ and $\theta$ values, buckling stresses $\tau_{l}^{e}, \tau_{g}^{e}$, and $\tau_{i}^{e}$ will theoretically be equal.

\section{Finite element analysis}

An elastic FEA is carried out in the ANSYS software [32] to study the influence of $d / t, a / h$ and $\theta$ on the shear buckling stress of CSWs and to see if the analytical formulas are correct. According to Yi et al. [15], $a / h=0.1 \sim 0.2$ and $d / t=10 \sim 25$ in actual bridges. In this study, conservatively adopting $a / h=0.1 \sim 0.3$ and $d / t=10 \sim 30$, while other geometric parameters are taken as: $\theta=30^{\circ} \sim 45^{\circ}$ and $t=8 \mathrm{~mm} \sim 12 \mathrm{~mm}$. The span of the girders is set as $20 q$. In addition, the width and the thickness of flanges are $8 d$ and $80 \mathrm{~mm}$ respectively. There are three stiffeners and their behavior is assumed to be rigid.

\subsection{Finite element model}

A shell element (shell 181) is used to model the girders with CSWs. The finite element model is shown in Fig. 6 and the boundary conditions are given in Table 9. A concentrated load is applied at the midspan (point 2). All models adopt a symmetry boundary condition with roller supports at the intersection nodes of the bottom flange and the end stiffeners, and Point 1 restrained in the longitudinal direction ( $x$ direction) [26]. In addition, Point 1 and Point 2 are restrained in the lateral direction ( $z$ direction) to avoid lateral-torsion buckling.

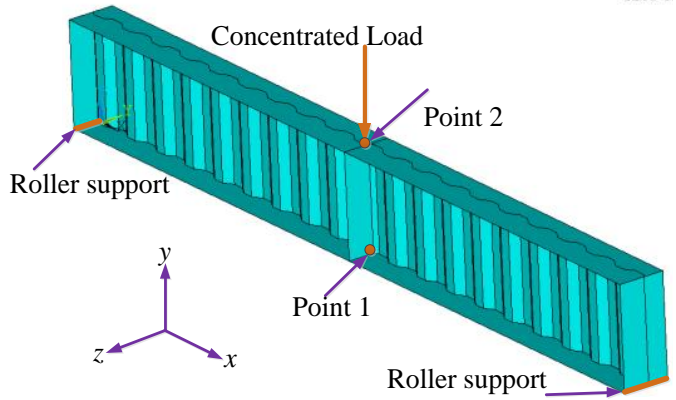

Fig. 6 Load and boundary conditions of a girder with CSWs

Table 9

Boundary conditions of finite element models

\begin{tabular}{ccccccc}
\hline Boundary & $\delta_{x}$ & $\delta_{y}$ & $\delta_{z}$ & $\theta_{x}$ & $\theta_{y}$ & $\theta_{z}$ \\
\hline Roller support & $\circ$ & $\bullet$ & $\bullet$ & $\bullet$ & $\bullet$ & $\circ$ \\
Point 1 & $\bullet$ & $\circ$ & $\bullet$ & $\circ$ & $\circ$ & $\circ$ \\
Point 2 & $\circ$ & $\circ$ & $\bullet$ & $\circ$ & $\circ$ & $\circ$ \\
\hline
\end{tabular}

Note: ○: Free; •: Restrained.

In this study, the number of elements per sub-panel is 6 , as suggested by Eldib [3], and the element mesh size is $a / 6$. The elastic modulus and Poisson's ratio of steel are taken as $210000 \mathrm{MPa}$ and 0.3 respectively. Fig. 7 represents three shear buckling modes of CSWs.

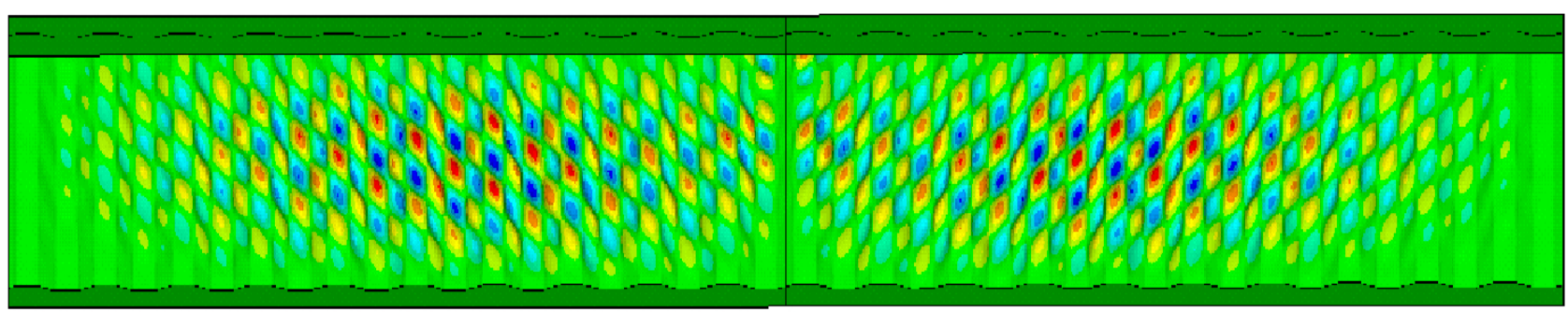

(a) Local shear buckling

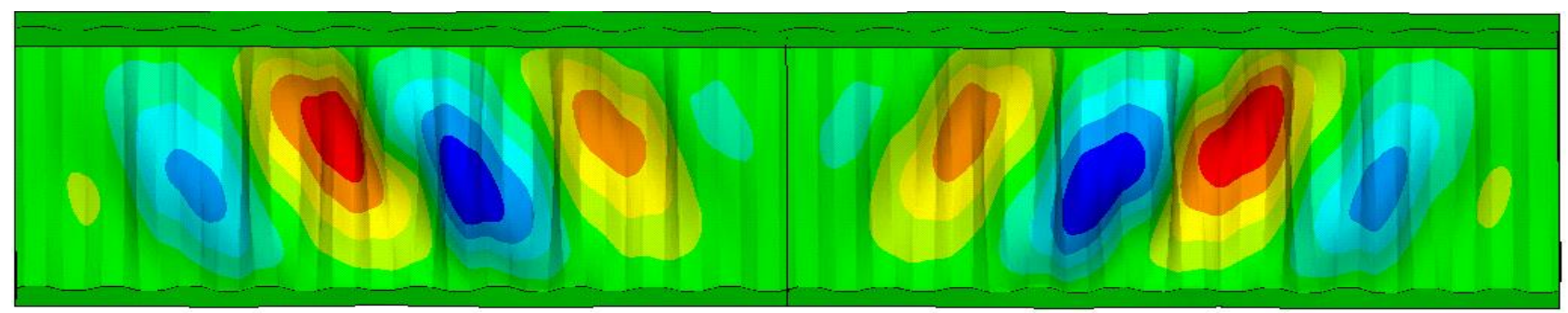

(b) Global shear buckling

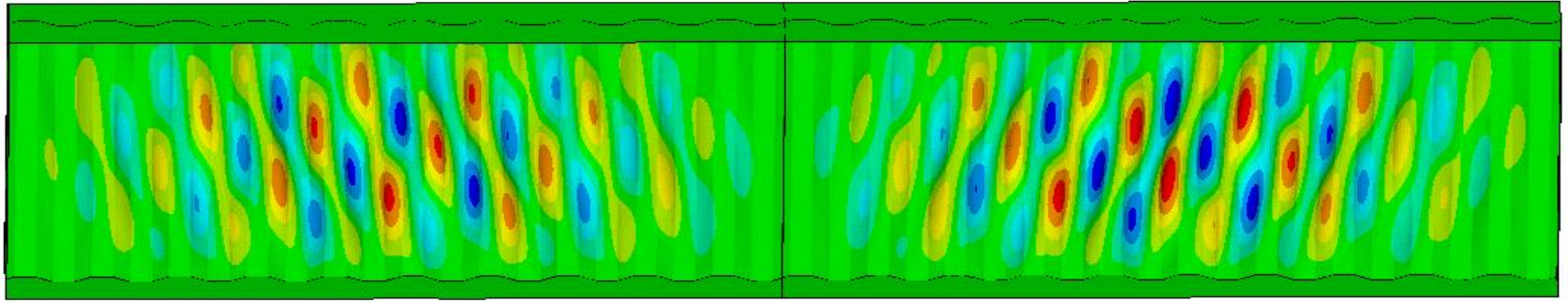

(c) Interactive shear buckling

Fig. 7 Three shear buckling modes 


\subsection{Parametric analysis}

Theoretically, in the case of $a=c$, and equal $d / t, a / h$ and $\theta$, the elastic local shear buckling stress $\tau_{l}^{e}$, global shear buckling stress $\tau_{g}^{e}$, and interactive shear buckling stress $\tau_{i}^{e}$ should be equal. It can be seen from Fig. 8 that for CSWs with different web thicknesses but equal $d / t, a / h$ and $\theta$ when $a=c$, the FEA results $\tau_{F E A}^{e}$ are indeed practically the equal which is in good agreement with the theoretical expectations. $\tau_{F E A}^{e}$ is the maximum shear stress of CSWs from FEA. It is worth mentioning that the $d / t, a / h$ and $\theta$ are the determining factors, rather than $t$. In what follows, $t=10 \mathrm{~mm}$ is adopted.

The influence of $d / t$, a/h and $\theta$ on the elastic shear buckling stress is shown in Tables 10-12 and Figs. 9-10. It can be seen from Tables 10-12 and Figs. 9-10 that, apart from the global shear buckling modes with small $d / t$ and small $a / h$, the FEA results agree well with the theoretical results $\tau_{c r}^{e}$. The elastic shear buckling stress of CSWs $\tau_{c r}^{e}$ is controlled by the minimum value of local, global and interactive shear buckling stress, and can be calculated by Eq. (32).

$$
\tau_{c r}^{e}=\operatorname{minimum}\left(\tau_{l, s}^{e}, \tau_{g, s}^{e}, \tau_{i}^{e}\right)
$$

It can be seen from Fig. 9 that the shear buckling stress greatly decreases with the increase of $d / t$. That is to say, improving the thickness of CSWs is an effective method to improve the shear buckling stress of CSWs. It can be seen from Fig. 10 (a) that the shear buckling stress increases with the increase of $a / h$. However, with the increase of $a / h$, the buckling stress $\tau_{F E A}^{e}$ shows a converging trend. It can be seen from Fig. 10 (b) that the shear buckling stress increases with the increase of $\theta$. Though improving $\theta$ can improve the shear buckling stress, $\theta=30^{\circ} \sim 45^{\circ}$ is adopted in actual engineering because larger $\theta$ need more steel and is not economic.

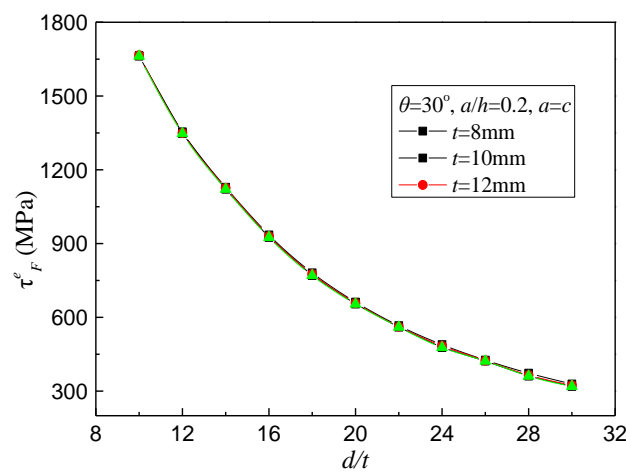

(b) $a / h=0.2$

Fig. 8 Influence of $t$ on the elastic shear buckling stress $\tau_{F E A}^{e}$

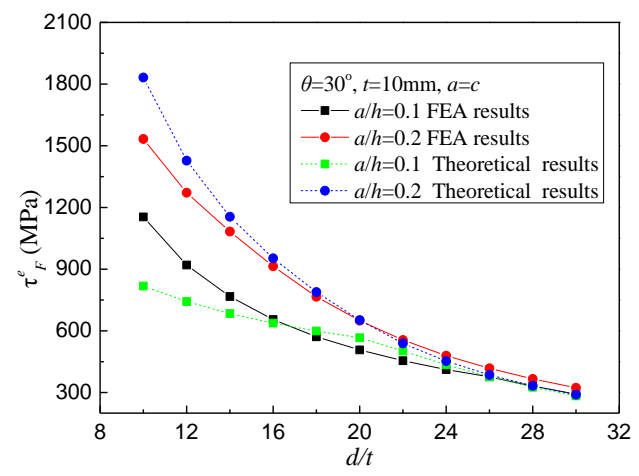

(a) $\theta=30^{\circ}$

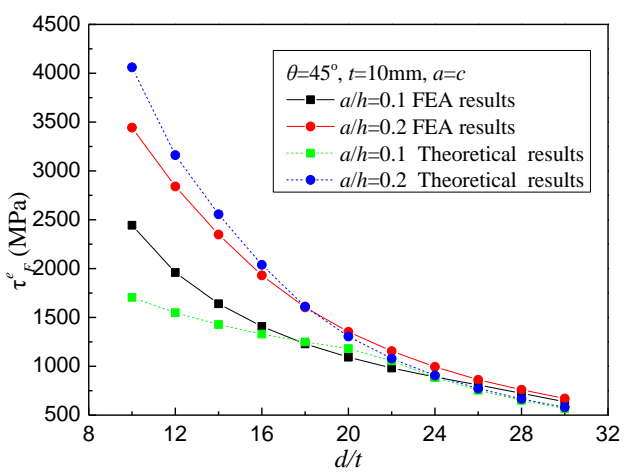

(b) $\theta=45^{\circ}$

Fig. 9 Influence of $d / t$ on the elastic shear buckling stress

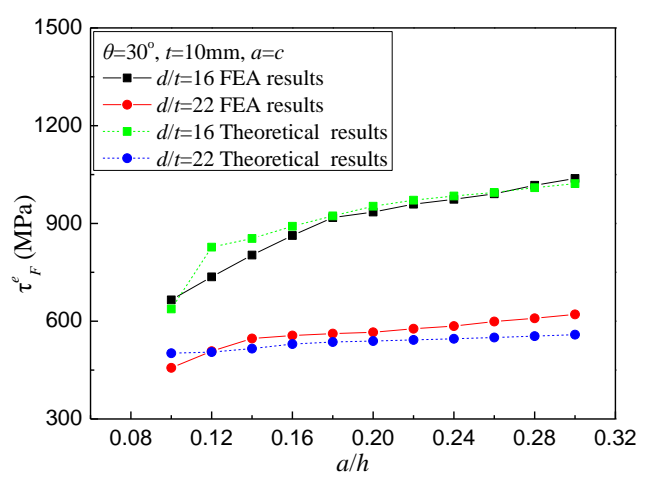

(a) $a / h$

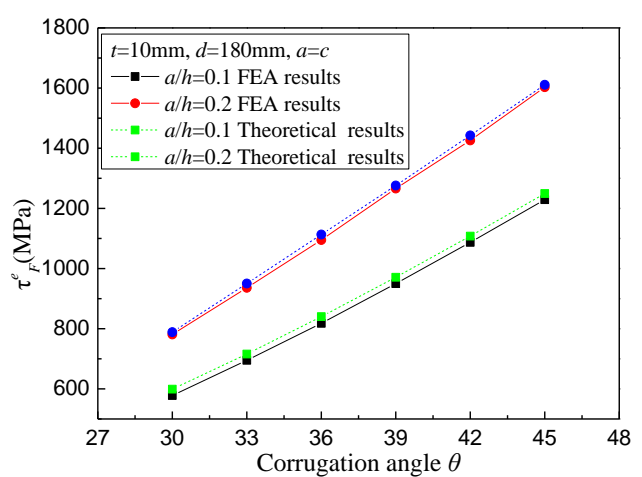

(b) $\theta$

Fig. 10 Influence of $a / h$ and $\theta$ on the elastic shear buckling stress 
Table 10

Elastic shear buckling stress of CSWs with different $d / t$

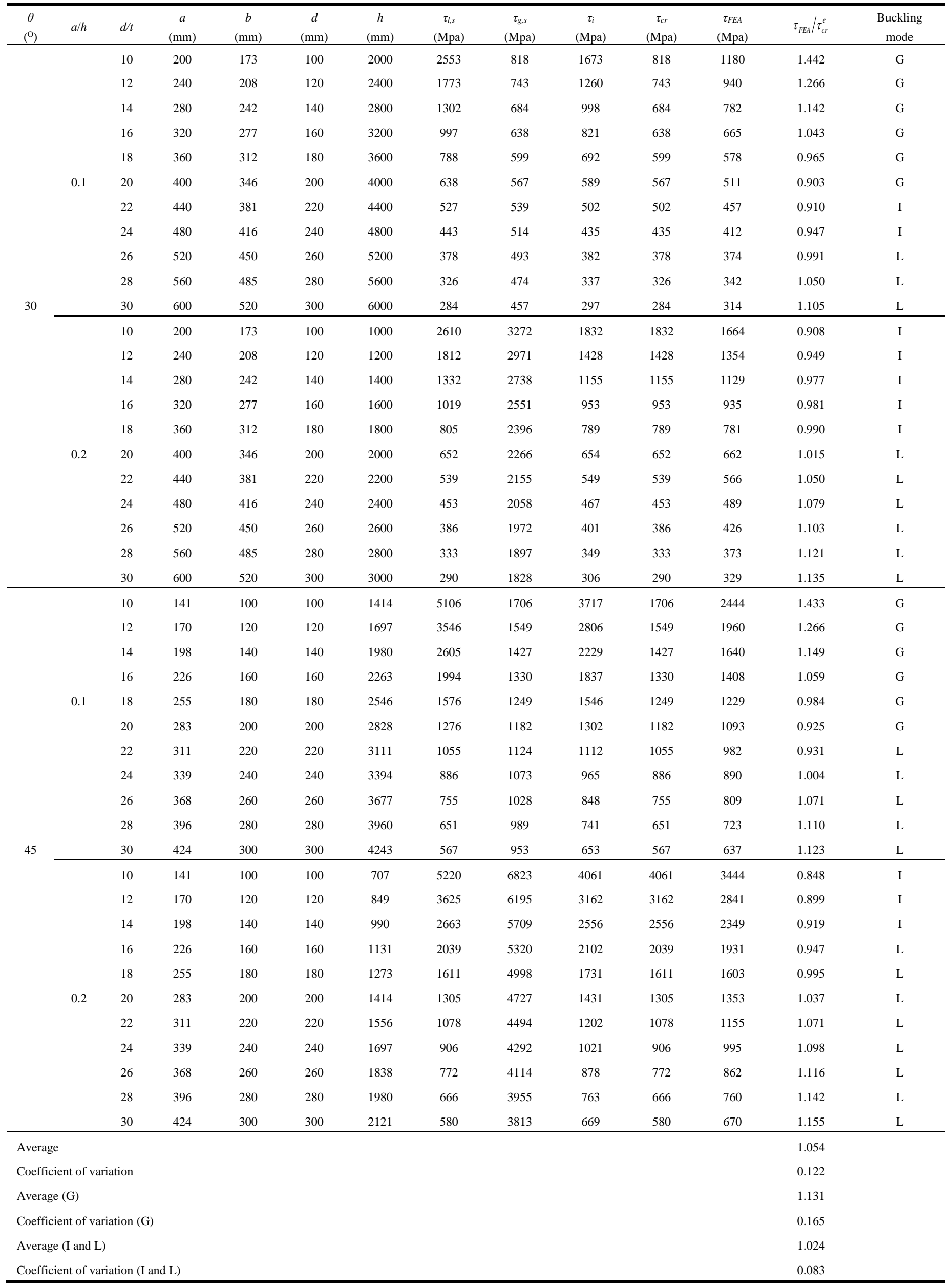


Table 11

Elastic shear buckling stress of CSWs with different $a / h$

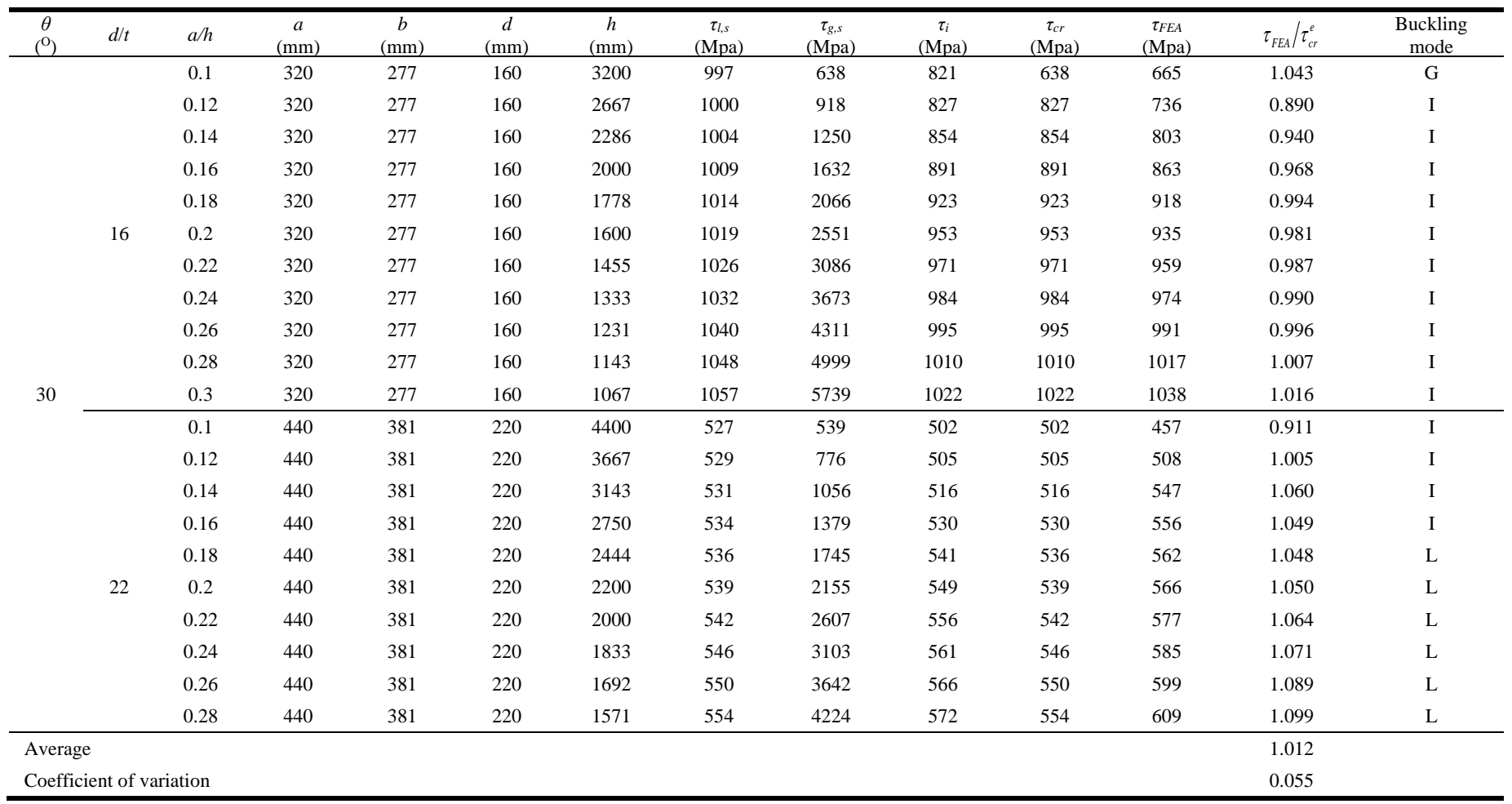

Table 12

Elastic shear buckling stress of CSWs with different $\theta$

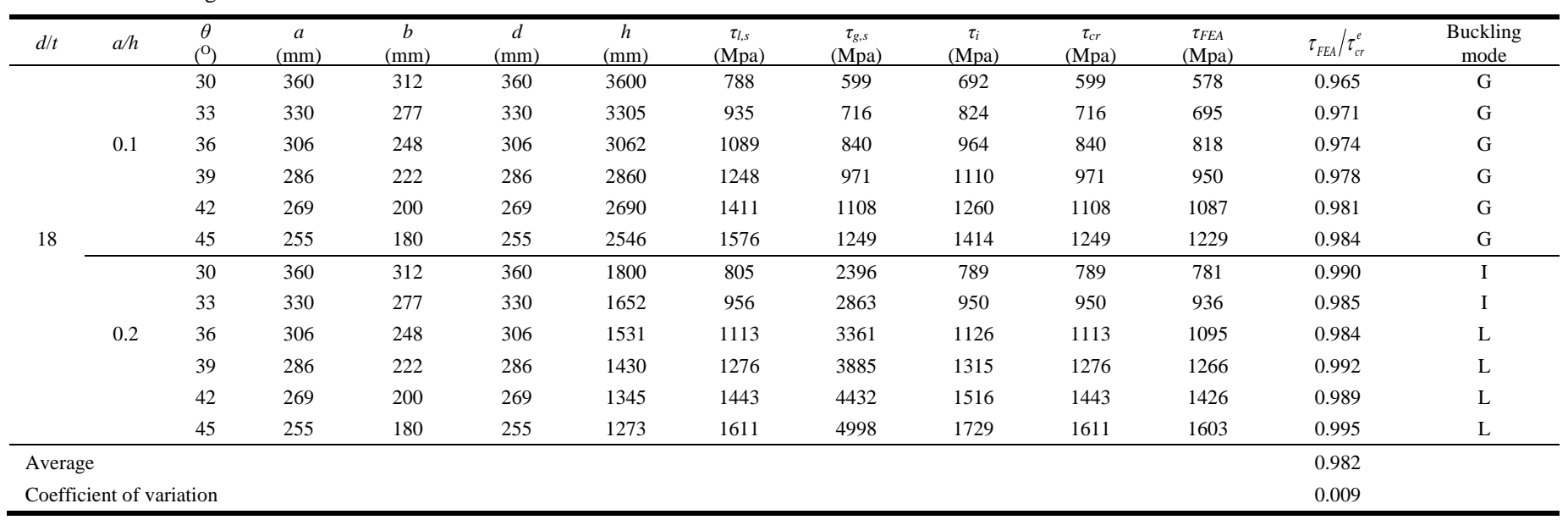

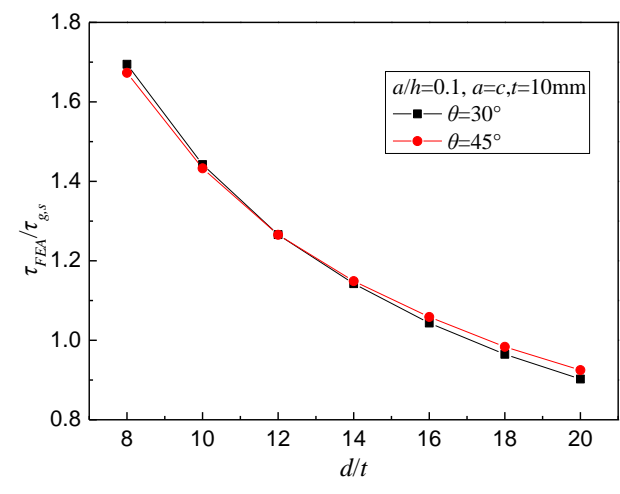

(a) $d / t$

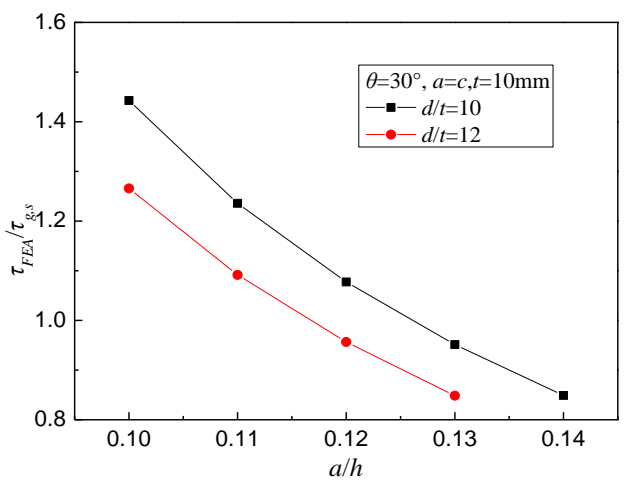

(b) $a / h$

Fig. 11 Influence of $d / t$ and $a / h$ on $\tau_{F E A}^{e} / \tau_{g, s}^{e}$

The boundary condition of the global buckling mode is complicated. Fig. 11 shows the ratios of $\tau_{F E A}^{e}$ to $\tau_{g, s}^{e}$ varies with $d / t$ and $a / h$ in the case of $\tau_{g, s}^{e}<$ minimum $\left(\tau_{l, s}^{e}, \tau_{i}^{e}\right)$ which the global buckling becomes the primary failure mode. It can be seen from Fig. 11 that $\tau_{F E A}^{e} / \tau_{g, s}^{e}$ decreases with the increase of $d / t$ and $a / h$. That is to say, the constraint effect of flanges on CSWs gradually decreases with the increase of $d / t$ and $a / h$. Although the ratios of $\tau_{F E A}^{e}$ to $\tau_{g, s}^{e}$ are high for small $d / t$ and $a / h$, the simple support boundary condition is adopted for conservative consideration. 


\section{Shear design of CSWs}

Considering material nonlinearity and yielding, the formula for the elastic shear buckling stress cannot keep up with the actual. So a formula which can reflect the actual shear strength needs to be proposed. Important work has been done by Elgaaly [22], Driver [23], El Metwally [17], Yi et al. [15], Sause [31], Nie et al.[21]. The previous design formulas may be not precise because adopting the interactive shear buckling stress formula which based on the relationship between the local and global shear buckling stresses, and the yield stress only. All the previous elastic interactive formulas adopt $\left(1 / \tau_{i}^{e}\right)^{n}=\left(1 / \tau_{l}^{e}\right)^{n}+\left(1 / \tau_{g}^{e}\right)^{n}, n=1 \sim 4$ [15], show that the interactive shear buckling stress is the minimum value of the three shear buckling modes, which is not reasonable and lacks theoretical support. Unlike the past, in this study, the formulas for the elastic global and interactive shear buckling stresses proposed in section 2 are used in the design formula.

Eq. (33) was provided to calculate the ultimate shear strength of CSWs in the design manual for PC bridges with CSWs [33].

$$
\tau_{c r}=\tau_{y} \times\left\{\begin{array}{cc}
1 & \lambda_{c r} \leq 0.6 \\
1-0.614\left(\lambda_{c r}-0.6\right) & 0.6 \leq \lambda_{c r} \leq \sqrt{2} \\
1 / \lambda_{c r}^{2} & \lambda_{c r}>\sqrt{2}
\end{array}\right.
$$

Table 13

Comparison between the shear strength calculated by the proposed design formulas and the test results obtained by Elgaaly et al.[22]

\begin{tabular}{|c|c|c|c|c|c|c|c|c|c|c|c|c|c|c|c|}
\hline Specimen & $e / h$ & $\begin{array}{c}a \\
(\mathrm{~mm})\end{array}$ & $\begin{array}{c}b \\
(\mathrm{~mm})\end{array}$ & $\begin{array}{c}\theta \\
(\mathrm{O})\end{array}$ & $\begin{array}{c}h \\
(\mathrm{~mm})\end{array}$ & $\begin{array}{c}t \\
(\mathrm{~mm})\end{array}$ & $\begin{array}{c}\tau_{y} \\
(\mathrm{Mpa})\end{array}$ & $\begin{array}{c}\tau_{e} \\
(\mathrm{Mpa})\end{array}$ & $\lambda_{c r}$ & $\begin{array}{c}\tau_{c r} \\
(\mathrm{Mpa})\end{array}$ & $\tau_{e} \tau_{c r}$ & $\tau_{e} \tau_{n, A}$ & $\tau_{e} \tau_{n, B}$ & $\tau_{e} \tau_{n, M}$ & $\tau_{e} \tau_{n, Y}$ \\
\hline V-PILOTA & 1 & 38.1 & 25.4 & 45 & 304.8 & 0.7823 & 358 & 346.54 & 1.03 & 262.5 & 1.320 & 1.404 & 1.349 & 1.316 & 1.363 \\
\hline V-PILOTB & 1 & 38.1 & 25.4 & 45 & 304.8 & 0.7849 & 368 & 347.54 & 1.05 & 267.4 & 1.300 & 1.177 & 1.132 & 1.109 & 1.149 \\
\hline V121216A & 1 & 38.1 & 25.4 & 45 & 304.8 & 0.6375 & 389.8 & 257.3 & 1.32 & 216.4 & 1.189 & 1.159 & 1.132 & 1.178 & 1.194 \\
\hline V121216B & 1 & 38.1 & 25.4 & 45 & 304.8 & 0.7645 & 383.8 & 375.8 & 1.10 & 267.0 & 1.408 & 1.464 & 1.41 & 1.405 & 1.452 \\
\hline V181216B & 0.67 & 38.1 & 25.4 & 45 & 457.2 & 0.6096 & 356.8 & 334.9 & 1.33 & 197.0 & 1.700 & 1.649 & 1.64 & 1.768 & 1.993 \\
\hline V181216C & 0.67 & 38.1 & 25.4 & 45 & 457.2 & 0.7595 & 391.5 & 343.9 & 1.12 & 267.1 & 1.288 & 1.325 & 1.316 & 1.385 & 1.539 \\
\hline V181816A & 1 & 38.1 & 25.4 & 45 & 457.2 & 0.635 & 341.3 & 257.2 & 1.25 & 205.5 & 1.252 & 1.22 & 1.228 & 1.311 & 1.449 \\
\hline V181816B & 1 & 38.1 & 25.4 & 45 & 457.2 & 0.7366 & 354.2 & 285.4 & 1.10 & 246.3 & 1.159 & 1.203 & 1.185 & 1.232 & 1.359 \\
\hline V241216A & 0.5 & 38.1 & 25.4 & 45 & 609.6 & 0.635 & 341.3 & 195.1 & 1.25 & 205.2 & 0.951 & 0.996 & 1.01 & 1.129 & 1.374 \\
\hline V241216B & 0.5 & 38.1 & 25.4 & 45 & 609.6 & 0.7874 & 339.2 & 277.7 & 1.03 & 250.1 & 1.110 & 1.238 & 1.252 & 1.343 & 1.523 \\
\hline V121221A & 1 & 41.9 & 23.4 & 55 & 304.8 & 0.6299 & 383.8 & 240.8 & 1.46 & 179.8 & 1.339 & 1.27 & 1.226 & 1.277 & 1.236 \\
\hline V121221B & 1 & 41.9 & 23.4 & 55 & 304.8 & 0.7849 & 383.8 & 302.9 & 1.17 & 248.9 & 1.217 & 1.227 & 1.194 & 1.202 & 1.189 \\
\hline V122421A & 2 & 41.9 & 23.4 & 55 & 304.8 & 0.6756 & 358 & 210 & 1.32 & 200.7 & 1.046 & 1.023 & 0.998 & 1.028 & 0.996 \\
\hline V122421B & 2 & 41.9 & 23.4 & 55 & 304.8 & 0.7823 & 368 & 256.5 & 1.15 & 243.3 & 1.054 & 1.073 & 1.04 & 1.041 & 1.031 \\
\hline V181221A & 0.67 & 41.9 & 23.4 & 55 & 457.2 & 0.6096 & 333.4 & 221.7 & 1.41 & 167.1 & 1.327 & 1.274 & 1.236 & 1.302 & 1.356 \\
\hline V181221B & 0.67 & 41.9 & 23.4 & 55 & 457.2 & 0.762 & 349.6 & 280.7 & 1.16 & 230.0 & 1.220 & 1.236 & 1.204 & 1.23 & 1.29 \\
\hline V181821A & 1 & 41.9 & 23.4 & 55 & 457.2 & 0.635 & 318.3 & 194.4 & 1.32 & 176.6 & 1.101 & 1.07 & 1.046 & 1.095 & 1.13 \\
\hline V181821B & 1 & 41.9 & 23.4 & 55 & 457.2 & 0.7366 & 343.9 & 277.2 & 1.19 & 219.9 & 1.260 & 1.26 & 1.234 & 1.268 & 1.326 \\
\hline V241221A & 0.5 & 41.9 & 23.4 & 55 & 609.6 & 0.6096 & 351.7 & 207.8 & 1.45 & 166.7 & 1.247 & 1.177 & 1.159 & 1.26 & 1.468 \\
\hline V241221B & 0.5 & 41.9 & 23.4 & 55 & 609.6 & 0.762 & 368.5 & 272.6 & 1.19 & 235.1 & 1.159 & 1.157 & 1.165 & 1.248 & 1.399 \\
\hline V121232A & 1 & 49.8 & 26.4 & 62.5 & 304.8 & 0.6401 & 383.8 & 210.8 & 1.70 & 132.2 & 1.594 & 1.83 & 1.781 & 1.831 & 1.803 \\
\hline V121232B & 1 & 49.8 & 26.4 & 62.5 & 304.8 & 0.7798 & 369.9 & 257.1 & 1.37 & 194.4 & 1.323 & 1.594 & 1.536 & 1.596 & 1.499 \\
\hline V121832A & 1.5 & 49.8 & 26.4 & 62.5 & 304.8 & 0.6401 & 405.8 & 176.6 & 1.75 & 132.2 & 1.336 & 1.526 & 1.488 & 1.526 & 1.511 \\
\hline V121832B & 1.5 & 49.8 & 26.4 & 62.5 & 304.8 & 0.9195 & 324.2 & 190.3 & 1.09 & 226.7 & 0.840 & 0.963 & 0.947 & 0.964 & 0.906 \\
\hline V122432A & 2 & 49.8 & 26.4 & 62.5 & 304.8 & 0.6401 & 411.8 & 159.5 & 1.76 & 132.2 & 1.206 & 1.376 & 1.343 & 1.377 & 1.365 \\
\hline V122432B & 2 & 49.8 & 26.4 & 62.5 & 304.8 & 0.7772 & 366 & 206.4 & 1.37 & 192.9 & 1.070 & 1.289 & 1.242 & 1.29 & 1.211 \\
\hline V181232A & 0.67 & 49.8 & 26.4 & 62.5 & 457.2 & 0.5969 & 318.2 & 188.9 & 1.67 & 113.7 & 1.661 & 1.895 & 1.842 & 1.899 & 1.921 \\
\hline V181232B & 0.67 & 49.8 & 26.4 & 62.5 & 457.2 & 0.7493 & 347.5 & 233.6 & 1.39 & 178.4 & 1.309 & 1.563 & 1.507 & 1.569 & 1.545 \\
\hline V181832A & 1 & 49.8 & 26.4 & 62.5 & 457.2 & 0.6096 & 397.8 & 189.8 & 1.83 & 118.6 & 1.600 & 1.797 & 1.757 & 1.801 & 1.854 \\
\hline V181832B & 1 & 49.8 & 26.4 & 62.5 & 457.2 & 0.7493 & 334.6 & 229.4 & 1.37 & 177.2 & 1.295 & 1.547 & 1.49 & 1.552 & 1.518 \\
\hline V241232A & 0.5 & 49.8 & 26.4 & 62.5 & 609.6 & 0.6223 & 388.5 & 182 & 1.78 & 123.1 & 1.478 & 1.662 & 1.622 & 1.674 & 1.798 \\
\hline V241232B & 0.5 & 49.8 & 26.4 & 62.5 & 609.6 & 0.762 & 337.1 & 218.3 & 1.35 & 181.6 & 1.202 & 1.43 & 1.38 & 1.447 & 1.496 \\
\hline V121809A & 1.5 & 19.8 & 11.9 & 50 & 304.8 & 0.7061 & 330.2 & 293.3 & 0.79 & 291.1 & 1.007 & 1.256 & 1.163 & 1.066 & 1.119 \\
\hline V121809C & 1.5 & 19.8 & 11.9 & 50 & 304.8 & 0.6325 & 385.8 & 285.9 & 0.88 & 318.9 & 0.896 & 1.048 & 1.003 & 0.97 & 1.04 \\
\hline V122409A & 2 & 19.8 & 11.9 & 50 & 304.8 & 0.7137 & 338.1 & 265.6 & 0.80 & 296.6 & 0.895 & 1.111 & 1.03 & 0.947 & 0.994 \\
\hline V122409C & 2 & 19.8 & 11.9 & 50 & 304.8 & 0.6629 & 358 & 286 & 0.84 & 305.4 & 0.937 & 1.13 & 1.062 & 1.001 & 1.063 \\
\hline V181209A & 0.67 & 19.8 & 11.9 & 50 & 457.2 & 0.5588 & 397.8 & 316.7 & 1.39 & 205.2 & 1.544 & 1.672 & 1.621 & 1.722 & 1.883 \\
\hline V181209C & 0.67 & 19.8 & 11.9 & 50 & 457.2 & 0.6096 & 341.6 & 318.3 & 1.26 & 203.7 & 1.563 & 1.694 & 1.65 & 1.73 & 1.779 \\
\hline V181809A & 1 & 19.8 & 11.9 & 50 & 457.2 & 0.6096 & 356.7 & 295 & 1.28 & 206.7 & 1.427 & 1.551 & 1.507 & 1.584 & 1.637 \\
\hline V181809C & 1 & 19.8 & 11.9 & 50 & 457.2 & 0.6223 & 322.4 & 272.6 & 1.21 & 200.7 & 1.358 & 1.468 & 1.436 & 1.495 & 1.525 \\
\hline V241209A & 0.5 & 19.8 & 11.9 & 50 & 609.6 & 0.6223 & 349.6 & 186.4 & 1.69 & 122.9 & 1.517 & 1.553 & 1.505 & 1.565 & 1.654 \\
\hline V241209C & 0.5 & 19.8 & 11.9 & 50 & 609.6 & 0.635 & 358 & 204.8 & 1.70 & 124.2 & 1.649 & 1.686 & 1.635 & 1.698 & 1.792 \\
\hline \multirow{2}{*}{\multicolumn{11}{|c|}{$\begin{array}{l}\text { Average } \\
\text { Coefficient of variation (C.V.) }\end{array}$}} & 1.270 & 1.363 & 1.326 & 1.367 & 1.422 \\
\hline & & & & & & & & & & & 0.175 & 0.182 & 0.182 & 0.194 & 0.198 \\
\hline
\end{tabular}

For conservative consideration, $\tau_{c}^{e^{*}}$ adopts Eq. (32) introducing a modification factor.

where $\tau_{y}$ is the shear yield stress and can be calculated by $\tau_{y}=f_{y} / \sqrt{3}, f_{y}$ is the uniaxial yield stress.

Eq. (33) is verified by using published experimental results of 102 specimens obtained by Elgaaly et al. [22], Lindner et al. [34], Peil [35], Gil et al. [36], Abbas et al. [18], Moon et al.[24]. Tables 13-18 show a comparison between the shear strength calculated by Eq. (33) and four previous design methods and experimental results $\tau_{e}\left[31\right.$ ]. In Tables 13-18, $\tau_{n, A}, \tau_{n, B}, \tau_{n, M}, \tau_{n, Y}$ are the shear strength of CSWs calculated by the four previous design methods proposed by Driver [23], Sause [31], El Metwally [17], Yi et al. [15]. Fig. 12 shows the normalized shear capacity $\tau_{e} / \tau_{y}$ and $\tau_{e} / \tau_{c r}$ versus $\lambda_{c r}$. It can be seen that all the tests have a ratio $\tau_{e} / \tau_{c r} \geq 0.8$. $\tau_{c r}^{e^{*}}=\operatorname{minimum}\left(0.85 \tau_{l, s}^{e}, \tau_{g, s}^{e}, 0.85 \tau_{i}^{e}\right)$ 
Table 14

Comparison between the shear strength calculated by the proposed design formulas and the test results obtained by Lindner et al. [34]

\begin{tabular}{|c|c|c|c|c|c|c|c|c|c|c|c|c|c|c|c|}
\hline Specimen & $e / h$ & $\begin{array}{c}a \\
(\mathrm{~mm})\end{array}$ & $\begin{array}{c}b \\
(\mathrm{~mm})\end{array}$ & $\begin{array}{c}\theta \\
\left({ }^{\mathrm{O}}\right)\end{array}$ & $\begin{array}{c}h \\
(\mathrm{~mm})\end{array}$ & $\begin{array}{c}t \\
(\mathrm{~mm})\end{array}$ & $\begin{array}{c}\tau_{y} \\
(\mathrm{Mpa})\end{array}$ & $\begin{array}{c}\tau_{e} \\
(\mathrm{Mpa})\end{array}$ & $\lambda_{c r}$ & $\begin{array}{c}\tau_{c r} \\
(\mathrm{Mpa})\end{array}$ & $\tau_{e} \tau_{c r}$ & $\tau_{e} / \tau_{n, A}$ & $\tau_{e} \tau_{n, B}$ & $\tau_{e} \tau_{n, M}$ & $\tau_{e} \tau_{n, Y}$ \\
\hline L1A & 0.98 & 140 & 50 & 45 & 994 & 1.94 & 169 & 145.5 & 1.00 & 127.1 & 1.144 & 1.259 & 1.210 & 1.190 & 1.235 \\
\hline L1B & 0.99 & 140 & 50 & 45 & 994 & 2.59 & 193 & 194.5 & 0.80 & 168.9 & 1.152 & 1.426 & 1.316 & 1.202 & 1.266 \\
\hline L2A & 1.04 & 140 & 50 & 45 & 1445 & 1.94 & 163 & 120.3 & 0.99 & 124.1 & 0.970 & 1.069 & 1.050 & 1.072 & 1.178 \\
\hline L2B & 1.04 & 140 & 50 & 45 & 1445 & 2.54 & 183 & 153.7 & 0.80 & 160.5 & 0.958 & 1.187 & 1.120 & 1.080 & 1.180 \\
\hline L3A & 1 & 140 & 50 & 45 & 2005 & 2.01 & 162 & 111.9 & 1.07 & 115.7 & 0.967 & 1.065 & 1.080 & 1.165 & 1.324 \\
\hline L3B & 1 & 140 & 50 & 45 & 2005 & 2.53 & 173 & 152.6 & 1.04 & 126.7 & 1.204 & 1.338 & 1.312 & 1.361 & 1.484 \\
\hline B1 & 1.33 & 140 & 50 & 45 & 600 & 2.1 & 197 & 165.1 & 0.99 & 150.0 & 1.100 & 1.225 & 1.174 & 1.136 & 1.122 \\
\hline B4 & 1.33 & 140 & 50 & 45 & 600 & 2.11 & 210 & 144.9 & 1.02 & 156.4 & 0.926 & 1.022 & 0.981 & 0.958 & 0.944 \\
\hline B4b & 1.33 & 140 & 50 & 45 & 600 & 2.11 & 210 & 171.8 & 1.02 & 156.4 & 1.098 & 1.212 & 1.163 & 1.136 & 1.120 \\
\hline B3 & 1.33 & 140 & 50 & 45 & 600 & 2.62 & 183 & 156.5 & 0.76 & 164.6 & 0.950 & 1.209 & 1.105 & 0.976 & 0.974 \\
\hline B2 & 1.17 & 140 & 50 & 45 & 600 & 2.62 & 182 & 173.8 & 0.76 & 164.0 & 1.060 & 1.350 & 1.234 & 1.088 & 1.086 \\
\hline M101 & 1 & 70 & 15 & 45 & 600 & 0.99 & 109 & 89.2 & 0.79 & 96.2 & 0.927 & 1.156 & 1.086 & 1.039 & 1.133 \\
\hline M102 & 1 & 70 & 15 & 45 & 800 & 0.99 & 110 & 100.0 & 1.00 & 83.0 & 1.205 & 1.354 & 1.326 & 1.370 & 1.500 \\
\hline M103 & 1 & 70 & 15 & 45 & 1000 & 0.95 & 123 & 88.4 & 1.34 & 67.4 & 1.313 & 1.443 & 1.413 & 1.526 & 1.748 \\
\hline M104 & 1 & 70 & 15 & 45 & 1200 & 0.99 & 109 & 87.4 & 1.49 & 48.9 & 1.789 & 1.922 & 1.862 & 1.975 & 2.200 \\
\hline L1 & 1.5 & 106 & 86.6 & 30 & 1000 & 2.1 & 237 & 181.1 & 0.83 & 203.0 & 0.892 & 1.081 & 1.013 & 0.962 & 1.039 \\
\hline L1 & 1.49 & 106 & 86.6 & 30 & 1000 & 3 & 260 & 203.6 & 0.65 & 251.3 & 0.810 & 1.107 & 1.003 & 0.884 & 0.931 \\
\hline L2 & 1.44 & 106 & 86.6 & 30 & 1498 & 2 & 217 & 200.3 & 0.98 & 166.5 & 1.203 & 1.354 & 1.336 & 1.384 & 1.531 \\
\hline L2 & 1.43 & 106 & 86.6 & 30 & 1498 & 3 & 232 & 201.4 & 0.91 & 188.0 & 1.071 & 1.229 & 1.186 & 1.145 & 1.201 \\
\hline No.1 & 1.33 & 102 & 85.5 & 33 & 850 & 2 & 205 & 161.7 & 0.78 & 182.0 & 0.889 & 1.116 & 1.024 & 0.921 & 0.960 \\
\hline No. 2 & 1.33 & 91 & 71.5 & 38.2 & 850 & 2 & 201 & 155.6 & 0.69 & 189.6 & 0.820 & 1.094 & 0.990 & 0.861 & 0.890 \\
\hline V1/1 & 9.46 & 144 & 102 & 45 & 298 & 2.05 & 172 & 111.3 & 0.92 & 138.7 & 0.803 & 0.938 & 0.899 & 0.863 & 0.821 \\
\hline $\mathrm{V} 1 / 2$ & 6.71 & 144 & 102 & 45 & 298 & 2.1 & 163 & 111.7 & 0.87 & 136.0 & 0.821 & 0.968 & 0.930 & 0.876 & 0.838 \\
\hline $\mathrm{V} 1 / 3$ & 3.36 & 144 & 102 & 45 & 298 & 2 & 172 & 135.9 & 0.94 & 136.2 & 0.997 & 1.161 & 1.113 & 1.077 & 1.020 \\
\hline $\mathrm{V} 2 / 3$ & 2.75 & 144 & 102 & 45 & 600 & 3 & 161 & 130.4 & 0.64 & 156.8 & 0.832 & 1.146 & 1.031 & 0.869 & 0.833 \\
\hline Average & & & & & & & & & & & 1.036 & 1.217 & 1.158 & 1.125 & 1.182 \\
\hline C.V. & & & & & & & & & & & 0.206 & 0.164 & 0.173 & 0.225 & 0.269 \\
\hline
\end{tabular}

Table 15

Comparison between the shear strength calculated by the proposed design formulas and the test results obtained by Gil et al. [36]

\begin{tabular}{|c|c|c|c|c|c|c|c|c|c|c|c|c|c|c|c|}
\hline Specimen & $e / h$ & $\begin{array}{c}a \\
(\mathrm{~mm})\end{array}$ & $\begin{array}{c}b \\
(\mathrm{~mm})\end{array}$ & $\begin{array}{c}\theta \\
(\mathrm{O})\end{array}$ & $\begin{array}{c}h \\
(\mathrm{~mm})\end{array}$ & $\begin{array}{c}t \\
(\mathrm{~mm})\end{array}$ & $\begin{array}{c}\tau_{y} \\
(\mathrm{Mpa})\end{array}$ & $\begin{array}{c}\tau_{e} \\
(\mathrm{Mpa})\end{array}$ & $\lambda_{c r}$ & $\begin{array}{c}\tau_{c r} \\
(\mathrm{Mpa})\end{array}$ & $\tau_{e} \tau_{c r}$ & $\tau_{e} \tau_{n, A}$ & $\tau_{e} \tau_{n, B}$ & $\tau_{e} \tau_{n, M}$ & $\tau_{e} / \tau_{n, Y}$ \\
\hline L1 & NA & 450 & 300 & 33.7 & 1500 & 4.8 & 144.3 & 103.8 & 1.174 & 93.4 & 1.111 & 1.188 & 1.167 & 1.188 & 1.103 \\
\hline L2 & NA & 550 & 300 & 32.2 & 1500 & 4.8 & 144.3 & 87 & 1.413 & 72.2 & 1.205 & 1.328 & 1.280 & 1.328 & 1.214 \\
\hline L3 & NA & 450 & 300 & 9.4 & 1500 & 4.8 & 144.3 & 74 & 1.192 & 91.9 & 0.806 & 0.847 & 0.836 & 0.870 & 0.905 \\
\hline $\mathrm{L} 4$ & NA & 550 & 300 & 10.6 & 1500 & 4.8 & 144.3 & 66 & 1.413 & 72.2 & 0.914 & 1.007 & 0.972 & 1.018 & 1.043 \\
\hline G1 & NA & 200 & 180 & 14.2 & 2000 & 4.8 & 144.3 & 114.4 & 0.917 & 116.2 & 0.985 & 1.133 & 1.090 & 1.053 & 1.092 \\
\hline G2 & NA & 160 & 50 & 33.4 & 2000 & 3.8 & 144.3 & 120.4 & 1.143 & 96.2 & 1.252 & 1.366 & 1.346 & 1.384 & 1.388 \\
\hline G3 & NA & 160 & 100 & 15.1 & 2000 & 3.8 & 144.3 & 122.7 & 1.391 & 74.2 & 1.653 & 1.852 & 1.786 & 1.866 & 1.871 \\
\hline I1 & NA & 320 & 100 & 24.0 & 2000 & 4.8 & 144.3 & 137.1 & 0.862 & 121.1 & 1.132 & 1.343 & 1.321 & 1.338 & 1.480 \\
\hline $\mathrm{I} 2$ & NA & 350 & 100 & 16.0 & 2000 & 3.8 & 144.3 & 74.6 & 1.265 & 85.4 & 0.874 & 1.054 & 1.038 & 1.174 & 1.481 \\
\hline Average & & & & & & & & & & & 1.103 & 1.235 & 1.204 & 1.247 & 1.286 \\
\hline C.V. & & & & & & & & & & & 0.233 & 0.234 & 0.229 & 0.230 & 0.231 \\
\hline
\end{tabular}

Note: NA-Not available

Table 16

Comparison between the shear strength calculated by the proposed design formulas and the test results ob-tained by Peil [35]

\begin{tabular}{|c|c|c|c|c|c|c|c|c|c|c|c|c|c|c|c|}
\hline Specimen & $e / h$ & $\begin{array}{c}a \\
(\mathrm{~mm})\end{array}$ & $\begin{array}{c}b \\
(\mathrm{~mm})\end{array}$ & $\begin{array}{c}\theta \\
(\mathrm{O}) \\
\end{array}$ & $\begin{array}{c}h \\
(\mathrm{~mm})\end{array}$ & $\begin{array}{c}t \\
(\mathrm{~mm}) \\
\end{array}$ & $\begin{array}{c}\tau_{y} \\
(\mathrm{Mpa})\end{array}$ & $\begin{array}{c}\tau_{e} \\
(\mathrm{Mpa})\end{array}$ & $\lambda_{c r}$ & $\begin{array}{c}\tau_{c r} \\
(\mathrm{Mpa})\end{array}$ & $\tau_{e} \tau_{c r}$ & $\tau_{e} / \tau_{n, A}$ & $\tau_{e} \tau_{n, B}$ & $\tau_{e} / \tau_{n, M}$ & $\tau_{e} \tau_{n, Y}$ \\
\hline SP1 & 2.19 & 146 & 104 & 45 & 800 & 2 & 177 & 140.7 & 1.03 & 129.9 & 1.083 & 1.189 & 1.143 & 1.120 & 1.080 \\
\hline SP2 & 2.19 & 170 & 80 & 45 & 800 & 2 & 172 & 134.3 & 1.18 & 110.6 & 1.214 & 1.274 & 1.254 & 1.277 & 1.209 \\
\hline SP3 & 2.19 & 185 & 65 & 45 & 800 & 2 & 168 & 130.7 & 1.27 & 99.2 & 1.317 & 1.397 & 1.358 & 1.400 & 1.322 \\
\hline SP4 & 2.25 & 117 & 83 & 45 & 800 & 2 & 172 & 144.5 & 0.82 & 148.8 & 0.971 & 1.188 & 1.097 & 0.988 & 0.986 \\
\hline SP5 & 2.25 & 136 & 64 & 45 & 800 & 2 & 168 & 138.1 & 0.94 & 133.0 & 1.038 & 1.163 & 1.118 & 1.059 & 1.059 \\
\hline SP6 & 2.25 & 148 & 52 & 45 & 800 & 2 & 169 & 137.1 & 1.02 & 125.1 & 1.096 & 1.204 & 1.156 & 1.134 & 1.135 \\
\hline SP2-2-400 1 & 2.5 & 170 & 80 & 45 & 400 & 2 & 152 & 100.6 & 1.06 & 109.1 & 0.922 & 1.029 & 1.001 & 1.001 & 0.934 \\
\hline SP2-2-400 2 & 2.5 & 170 & 80 & 45 & 400 & 2 & 152 & 110.5 & 1.06 & 109.1 & 1.013 & 1.130 & 1.099 & 1.099 & 1.026 \\
\hline SP2-2-800 1 & 1.25 & 170 & 80 & 45 & 800 & 2 & 157 & 111.8 & 1.13 & 106.0 & 1.054 & 1.119 & 1.094 & 1.100 & 1.049 \\
\hline SP2-2-800 2 & 1.25 & 170 & 80 & 45 & 800 & 2 & 157 & 111.0 & 1.13 & 106.0 & 1.047 & 1.112 & 1.087 & 1.093 & 1.042 \\
\hline SP2-3-600 1 & 1.67 & 170 & 80 & 45 & 600 & 3 & 170 & 167.8 & 0.77 & 151.9 & 1.104 & 1.396 & 1.280 & 1.134 & 1.109 \\
\hline SP2-3-600 2 & 1.67 & 170 & 80 & 45 & 600 & 3 & 170 & 171.7 & 0.77 & 151.9 & 1.130 & 1.429 & 1.310 & 1.161 & 1.135 \\
\hline SP2-3-1200 1 & 0.83 & 170 & 80 & 45 & 1200 & 3 & 170 & 170.0 & 0.79 & 150.2 & 1.132 & 1.415 & 1.298 & 1.161 & 1.188 \\
\hline SP2-3-1200 2 & 0.83 & 170 & 80 & 45 & 1200 & 3 & 170 & 173.9 & 0.79 & 150.2 & 1.158 & 1.447 & 1.327 & 1.188 & 1.215 \\
\hline SP2-4-800 1 & 1.25 & 170 & 80 & 45 & 800 & 4 & 188 & 188.0 & 0.62 & 186.0 & 1.011 & 1.415 & 1.269 & 1.063 & 1.033 \\
\hline SP2-4-800 2 & 1.25 & 170 & 80 & 45 & 800 & 4 & 188 & 188.6 & 0.62 & 186.0 & 1.014 & 1.419 & 1.273 & 1.066 & 1.036 \\
\hline SP2-4-1600 1 & 0.63 & 170 & 80 & 45 & 1600 & 4 & 189 & 189.6 & 0.63 & 185.9 & 1.020 & 1.418 & 1.278 & 1.104 & 1.147 \\
\hline SP2-4-1600 2 & 0.63 & 170 & 80 & 45 & 1600 & 4 & 189 & 191.3 & 0.63 & 185.9 & 1.029 & 1.432 & 1.290 & 1.114 & 1.158 \\
\hline SP2-8-800 1 & 1.25 & 170 & 80 & 45 & 800 & 8 & 156 & 205.0 & 0.28 & 156.0 & 1.314 & 1.858 & 1.656 & 1.319 & 1.314 \\
\hline SP2-8-800 2 & 1.25 & 170 & 80 & 45 & 800 & 8 & 156 & 215.4 & 0.28 & 156.0 & 1.381 & 1.952 & 1.739 & 1.385 & 1.381 \\
\hline Average & & & & & & & & & & & 1.102 & 1.349 & 1.256 & 1.148 & 1.128 \\
\hline C.V. & & & & & & & & & & & 0.110 & 0.173 & 0.145 & 0.100 & 0.104 \\
\hline
\end{tabular}


Table 17

Comparison between the shear strength calculated by the proposed design formulas and the test results ob-tained by Abbas et al.[18]

\begin{tabular}{|c|c|c|c|c|c|c|c|c|c|c|c|c|c|c|c|}
\hline Specimen & $e / h$ & $\begin{array}{c}a \\
(\mathrm{~mm})\end{array}$ & $\begin{array}{c}b \\
(\mathrm{~mm})\end{array}$ & $\begin{array}{c}\theta \\
(\mathrm{O})\end{array}$ & $\begin{array}{c}h \\
(\mathrm{~mm})\end{array}$ & $\begin{array}{c}t \\
(\mathrm{~mm})\end{array}$ & $\begin{array}{c}\tau_{y} \\
(\mathrm{Mpa})\end{array}$ & $\begin{array}{c}\tau_{e} \\
(\mathrm{Mpa})\end{array}$ & $\lambda_{c r}$ & $\begin{array}{c}\tau_{c r} \\
(\mathrm{Mpa})\end{array}$ & $\tau_{e} \tau_{c r}$ & $\tau_{e} \tau_{n, A}$ & $\tau_{e} \tau_{n, B}$ & $\tau_{e} \tau_{n, M}$ & $\tau_{e} \tau_{n, Y}$ \\
\hline G8A & 3 & 300 & 200 & 36.9 & 1500 & 6.3 & 268 & 228.6 & 0.88 & 221.9 & 1.030 & 1.207 & 1.12 & 1.017 & 1.023 \\
\hline G7A & 3 & 300 & 200 & 36.9 & 1500 & 6.3 & 268 & 243.1 & 0.88 & 221.9 & 1.095 & 1.282 & 1.188 & 1.077 & 1.084 \\
\hline $\mathrm{SC} 1$ & 3 & 300 & 200 & 36.9 & 1500 & 6.3 & 268 & 213.3 & 0.88 & 221.9 & 0.961 & 1.126 & 1.045 & 0.949 & 0.955 \\
\hline Average & & & & & & & & & & & 1.029 & 1.205 & 1.118 & 1.014 & 1.021 \\
\hline C.V. & & & & & & & & & & & 0.065 & 0.065 & 0.064 & 0.063 & 0.063 \\
\hline
\end{tabular}

Table 18.

Comparison between the shear strength calculated by the proposed design formulas and the test results obtained by Moon et al. [24]

\begin{tabular}{|c|c|c|c|c|c|c|c|c|c|c|c|c|c|c|c|}
\hline Specimen & $e / h$ & $\begin{array}{c}a \\
(\mathrm{~mm})\end{array}$ & $\begin{array}{c}b \\
(\mathrm{~mm})\end{array}$ & $\begin{array}{c}\theta \\
(\mathrm{O}) \\
\end{array}$ & $\begin{array}{c}h \\
(\mathrm{~mm})\end{array}$ & $\begin{array}{c}t \\
(\mathrm{~mm})\end{array}$ & $\begin{array}{c}\tau_{y} \\
(\mathrm{Mpa})\end{array}$ & $\begin{array}{c}\tau_{e} \\
(\mathrm{Mpa})\end{array}$ & $\lambda_{c r}$ & $\begin{array}{c}\tau_{c r} \\
(\mathrm{Mpa})\end{array}$ & $\tau_{e} / \tau_{c r}$ & $\tau_{e} / \tau_{n, A}$ & $\tau_{e} / \tau_{n, B}$ & $\tau_{e} / \tau_{n, M}$ & $\tau_{e} / \tau_{n, Y}$ \\
\hline MI2 & 0.803 & 250 & 220 & 17.2 & 2000 & 4 & 170.9 & 109.2 & 0.93 & 136.1 & 0.803 & 0.904 & 0.889 & 0.9 & 0.996 \\
\hline MI3 & 0.728 & 220 & 180 & 14.6 & 2000 & 4 & 170.9 & 105.4 & 1.01 & 127.6 & 0.826 & 0.872 & 0.837 & 0.822 & 0.899 \\
\hline MI4 & 0.887 & 220 & 180 & 18.7 & 2000 & 4 & 170.9 & 131.6 & 0.84 & 146.2 & 0.900 & 1.089 & 1.013 & 0.955 & 1.036 \\
\hline Average & & & & & & & & & & & 0.843 & 0.955 & 0.913 & 0.892 & 0.977 \\
\hline C.V. & & & & & & & & & & & 0.061 & 0.123 & 0.099 & 0.075 & 0.072 \\
\hline
\end{tabular}

Table 19

Comparison between test results and theoretical results

\begin{tabular}{|c|c|c|c|c|c|c|c|c|c|c|c|}
\hline \multirow[t]{2}{*}{ Specimen } & \multirow[t]{2}{*}{ Num. } & \multicolumn{2}{|c|}{$\tau_{e} \tau_{c r}$} & \multicolumn{2}{|c|}{$\tau_{e} / \tau_{n, A}$} & \multicolumn{2}{|c|}{$\tau_{e} \tau_{n, B}$} & \multicolumn{2}{|c|}{$\tau_{e} \tau_{n, M}$} & \multicolumn{2}{|c|}{$\tau_{e} / \tau_{n, Y}$} \\
\hline & & Mean & C.V. & Mean & C.V. & Mean & C.V. & Mean & C.V. & Mean & C.V. \\
\hline All & 102 & 1.146 & 0.199 & 1.297 & 0.188 & 1.242 & 0.187 & 1.230 & 0.214 & 1.269 & 0.231 \\
\hline$e / h>1$ and $\theta \geq 30^{\circ}$ & 46 & 1.028 & 0.138 & 1.221 & 0.165 & 1.151 & 0.151 & 1.086 & 0.145 & 1.083 & 0.148 \\
\hline
\end{tabular}

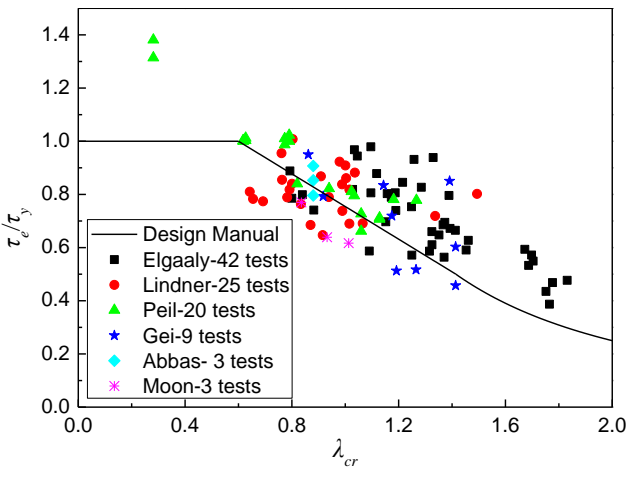

(a) $\tau_{e} / \tau_{y}$ versus $\lambda_{c r}$

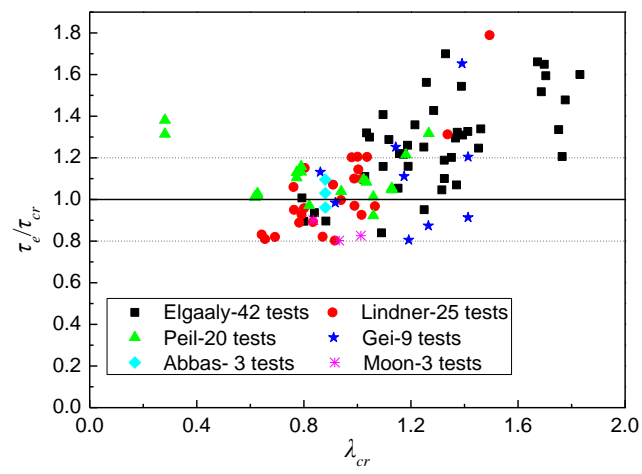

(b) $\tau_{e} / \tau_{c r}$ versus $\lambda_{c r}$

Fig. 12 Comparison between the shear strength calculated by Eq. (33) and the test results

For actual bridges, the distance between two adjacent stiffeners is much larger than the web height $h$, and $\theta$ always meets $\theta \geq 30^{\circ}$ [37], so the experimental results for the 46 specimens with $e / h>1$ and $\theta \geq 30^{\circ}$ are selected. $e / h$ is the shear span ratio[31]. The comparison between test results and theoretical results is given in Table 19. It can be seen that Eq. (33) which adopts the formulas for the elastic global and interactive shear buckling stresses proposed in this study provides on average much more accurate predictions of the shear strength of CSWs for the 102 specimens, and provides much more accurate predictions with the best average value and smallest coefficient of variation for the 46 specimens. So Eq. (33) is recommended to calculate the shear strength of CSWs.

It is worth mentioning that in Table 18, Reference [31] adopted the design corrugation depth of CSWs, however according to Reference [24], the negative error between the design corrugation depth and the measured corrugation depth can reach to $20 \%$. Because the buckling will initiate at the area that has the minimum measured corrugation depth [24], the minimum measured corrugation depth is adopted in this paper.

\section{Conclusions}

In this paper, the shear capacity of CSWs is theoretically and numerically studied, and the following main conclusions can be drawn:

(1) The whole CSW is assumed as an orthotropic plate, and the analytical formula for the global shear buckling stress of CSWs is derived by the Galerkin method. Simplified formulas of the global shear buckling coefficient $k_{g}$ for a four-edge simple support, for a four-edge fixed support, and for two edges constrained by flanges fixed and the other two edges simply supported are given.

(2) The folded plate composed of two adjacent panels is treated as an isotropic shallow shell, and the analytical formula for the interactive shear buckling stress of CSWs is derived by the Galerkin method. The interactive shear buckling coefficient table for CSWs with the same flat panel and inclined panel width is given.

(3) An elastic FEA is carried out to verify the analytical formulas and to study the influence of geometric parameters on the shear buckling stress of CSWs. Results show that the shear buckling stress greatly decreases with the increase of $d / t$, while increases with the increase of $a / h$ and $\theta$.

(4) A design formula for the shear strength of CSWs which adopts the formulas for the global and interactive shear buckling stresses proposed in this paper is assessed. From a comparison between the shear strength calculated by this design formula, calculated by four previous design formulas and measured in a series of published test results, it is found that the considered design formula provides good predictions for the shear strength of CSWs and can be recommended.

\section{Acknowledgments}

The supports from the National Natural Science Foundation of China (grant no.51378106) and the China Scholarship Council are gratefully acknowledged. 


\section{References}

[1] Hamilton R.W., "Behavior of welded girders with corrugated webs", Ph.D. Thesis, University of Maine, Orono, USA, 1993.

[2] Leblouba, M., Junaid, M.T., Barakat, S., Altoubat, S. and Maalej, M., "Shear buckling and stress distribution in trapezoidal web corrugated steel beams", Thin-Walled Structures, 113, 13-26, 2017

[3] Eldib M.H., "Shear buckling strength and design of curved corrugated steel webs for bridges", Journal of Constructional Steel Research, 65(12), 2129-2139, 2009.

[4] Timoshenko S.P. and Gere J.M., Theory of Elastic Stability 2nd ed., McGraw-Hill Book Company, New York, USA, 1961.

[5] Aggarwal K., Wu S.and Papangelis J., "Finite element analysis of local shear buckling in corrugated web beams", Engineering Structures, 162, 37-50, 2018

[6] Easley J.T. and McFarland D.E., "Buckling of light-gage corrugated metal shear diaphragms", Journal of the Structural Division, 95(7), 1497-1516, 1969.

[7] Easley J.T., "Buckling formulas for corrugated metal shear diaphragms", Journal of the Structural Division, 101(7), 1403-1417, 1975.

[8] Bergman S. and Reissner H., "Neuere probleme aus der flugzeugstatik-über die knickung von wellblechstreifen bei schubbeanspruchung", Zeitschrift für Flugzeugtechnik und Motorluftschiffahrt, 20(18), 475-481, 1929.

[9] Hlavacek V., "Shear instability of orthotropic panels", Acta Technica CSAV, 1, 134-158, 1968.

[10] Peterson J.P., Investigation of the Buckling Strength of Corrugated Webs in Shear, National Aeronautics and Space Administration, New York, 1960.

[11] Bergfelt A., Edlund B. and Leiva L., "Trapezoidally corrugated girder webs: shear buckling, patch loading", Ing. et Arch. Suisses, 111, 22-27, 1985.

[12] Ziemian R.D., Guide to Stability Design Criteria for Metal Structures, 6th ed., John Wiley \& Sons, New York, USA, 2010.

[13] El Metwally A. and Loov R.E., "Corrugated steel webs for prestressed concrete girders", Materials and Structures, 36(2), 127-134, 2003.

[14] Machimdamrong C., Watanabe E. and Utsunomiya T., "Shear buckling of corrugated plates with edges elastically restrained against rotation", International Journal of Structural Stability and Dynamics, 4(1), 89-104, 2004.

[15] Yi J., Gil H., Youm K. and Lee H., "Interactive shear buckling behavior of trapezoidally corrugated steel webs", Engineering Structures, 30(6), 1659-1666, 2008.

[16] Bergfelt A. and Leiva-Aravena L., "Shear buckling of trapezoidally corrugated girder webs", Division of Steel and Timber Structures, Chalmers University of Technology, Gothenburg, Publication S, 84(2), 1984.

[17] El Metwally A.S., "Prestressed composite girders with corrugated steel webs", Ph.D.Thesis, University of Calgary, Calgary, 1998.

[18] Abbas H., Sause R. and Driver R. "Shear strength and stability of high performance steel corrugated web girders", SSRC Conference, Seattle, USA, 361-387, 2002.

[19] Shiratani H., Ikeda H., Imai Y. and Kano K., "Flexural and shear behavior of composite bridge girder with corrugated steel webs around middle support", Doboku Gakkai Ronbunshu, 2003(724), 49-67, 2003.

[20] Sayed-Ahmed E.Y., "Plate girders with corrugated steel webs", Engineering Journal, 42(1), 1-13, 2005.

[21] Nie J.G., Zhu L., Tao M.X. and Tang L., "Shear strength of trapezoidal corrugated steel webs", China Civil Engineering Journal, 67(2), 223-236, 2013.

[22] Elgaaly M., Hamilton R.W. and Seshadri A., "Shear strength of beams with corrugated webs", Journal of Structural Engineering, 122(4), 390-398, 1996.

[23] Driver R.G., Abbas H.H. and Sause R., "Shear behavior of corrugated web bridge girders", Journal of Structural Engineering, 132(2), 195-203, 2006.

[24] Moon J., Yi J., Choi B.H. and Lee H.E., "Shear strength and design of trapezoidally corrugated steel webs", Journal of Constructional Steel Research, 65(5), 1198-1205, 2009.

[25] Hassanein M.F. and Kharoob O.F., "Shear buckling behavior of tapered bridge girders with steel corrugated webs", Engineering Structures, 74, 157-169, 2014

[26] Hassanein M.F., Elkawas A.A., EI Hadidy A.M. and Elchalakani M., "Shear analysis and design of high-strength steel corrugated web girders for bridge design", Engineering Structures, 146, 18-33, 2017

[27] Lekhnitskii S.G., Anisotropic Plates, Gordon and Breach Science Publishers, New York, USA, 1968.

[28] Batdorf S.B., A Simplified Method of Elastic-Stability Analysis for Thin Cylindrical Shells I: Donnell's Equation, Technical Report Archive Image Library, Langley Memorial Aeronautical Laboratory, Langley Field, USA, 1947

[29] Xu Q. and Wan S., Design and Application of PC Composite Box Girder Bridges with Corrugated Steel Webs, China Communication Press, Beijing, China, 2009.

[30] Li S.M., Stability Theory, China Communications Press, Beijing, China,1989.

[31] Sause R. and Braxtan T.N., "Shear strength of trapezoidal corrugated steel webs", Journal of Constructional Steel Research, 67(2), 223-236, 2011.

[32] ANSYS, ANSYS User's Manual Revision 12.1, ANSYS Inc., Canonsburg, USA, 2012

[33] Design Manual for PC Bridges with Corrugated Steel Webs., Research Committee for Hybrid Structures with Corrugated Steel Webs, 1998.

[34] Lindner J. and Aschinger R. "Biegetragfähigkeit von I-trägern mit trapezförmig profilierten stegen", Stahlbau, 57(12), 1988.

[35] Peil, U., "Statische versuche an trapezstegtragern untersuchung der querkraftbeanspruchbarkeit, Institut fur Stahlbau”, Braunschweig (Germany): Technischen Universitat Braunschweig, 1998.

[36] Gil H., Lee S., Lee J. and Lee H., "Shear buckling strength of trapezoidally corrugated steel webs for bridges", Transportation Research Record Journal of the Transportation Research Board, CD11-S, 473-480, 2005.

[37] Lindner J. and Huang B., "Beulwerte fur trapezformig profilierte bleche unter schubbeanspruchung", Stahlbau, 64(12), 370-373, 1995. 